\title{
Transfers of informal care time in the United States: the role of demographic differentials in intergenerational flows by age, sex, and racial and national background
}

\author{
Denys Dukhovnov ${ }^{1, *}$ and Emilio Zagheni ${ }^{2}$
}

\section{Abstract}

Recent work based on the American Time Use Survey (2011-2013) provided estimates matrices of "who provides care to whom" by age and sex within care activities in the U.S. In this paper, we build on that line of research by evaluating the strength of race, ethnicity, and national origin as proxy indicators of cultural propensities to engage in informal care. Our results point to several key differences and similarities between groups based on their characteristics. For example, we find that compared to other groups, native-born African American men exhibit the lowest child care participation and transfer rates, whereas foreign-born Hispanics of any race have significantly higher rates of daily participation in child care. Moreover, we find that the propensity to provide adult care is largely dependent on socio-economic characteristics and household structure. However, our models indicate that neither race/ethnicity nor nativity are strong predictors of the observed differences when household composition and socio-economic factors are taken into account. Thus, we believe that more complex cultural factors are at play. As an illustrative example of the consequences of demographic change, we introduce the care support ratio (CSR), which is a measure of macro-level dependency for non-market transfers. The application of the CSR indicates that future informal care time deficits may result from the growing care needs of the ageing population.

\footnotetext{
${ }^{1}$ Department of Demography, University of California, Berkeley, 2232 Piedmont Avenue, Berkeley, CA 94720, USA

${ }^{2}$ Max Planck Institute for Demographic Research, Rostock, Germany

${ }^{*}$ Correspondence to: Denys Dukhovnov, denys_dukhovnov@ berkeley.edu
} 


\section{Introduction}

The scope and the distribution of non-market household production throughout the population is culturally determined. While a large number of studies have examined this issue, most have restricted their focus to unidirectional care arrangements (e.g. adult children to parents, or parents to young children only), with relatively few considering the cultural propensities of caregivers to engage in broader simultaneous social network transfers. Cultural values often set specific expectations that can influence the caregiver's perceptions of the strain associated with his/her carerelated workload. Taking these expectations into account is especially important given that people of different nationalities, races, and ethnicities are influenced to varying degrees by labour market fluctuations and economic instability on the one hand, and by culturally-defined living arrangements on the other (Cravey and Mitra 2011). There is evidence suggesting that although caregivers who belong to racial and ethnic minority groups tend to be more economically challenged than white caregivers, they are two to three times more likely to provide direct care, primarily to younger generations. By contrast, compared to their non-white counterparts, white caregivers are more likely to provide indirect care, such as the coordination of carerelated tasks; and to spend less time on care activities overall (Fredriksen-Goldsen and Farwell 2005).

The present paper contributes to the literature on intergenerational economy and family relations by offering a perspective on differences in informal care time transfers by age, sex, race, and ethnicity in the United States. By giving additional consideration to factors beyond race/ethnicity and nativity, this paper sheds light on the extent to which race/ethnicity and national origin could be effectively used as substitutes for cultural affinity to transfer time in the form of informal care. In Section 2, we begin our treatment of the subject matter with a review of the existing research on racial, ethnic, and cultural aspects of informal care. Based on this review, we then formulate several hypotheses that we aim to test throughout our analysis. In Sections 3 and 4, we discuss the relevant features of our data, as well as our methodological approaches and considerations. In Section 5, we present our results, and propose a practical application of the informal care transfers matrix profiles as an extension to the set of metrics used to describe macroeconomic dependency. Finally, in Section 6 of the paper, we draw conclusions in light of our initial hypotheses, and discuss the implications of our results.

\section{Background}

Cultural belonging can be measured by a variety of indicators, all of which have strengths and weaknesses, depending on the socio-economic context and the completeness of the data used. Scholars generally recognise that race/ethnicity and national origin are strong predictors of an individual's behavioural patterns, including his/her levels of participation in informal care activities. There is evidence 
that the cultural and national backgrounds of whites and African Americans direct their sense of duty with respect to family and communal obligations in very different ways (Powers and Whitlatch 2016). Hispanic and Latino caregivers may also find that their care burden increases as the intensity of care they feel obliged to provide based on their perceived family obligations increases (Mendez-Luck et al. 2016). One meta-analysis of prior research has suggested that cultural belonging affects the outcomes of informal care transfers in part through the structure of the household, the number of generations co-residing in it, and the number of household members (Peek et al. 2000). For example, as the multigenerational living arrangements of African Americans are more conducive to reliance on family support and the distribution of caregiving tasks across family members, the load on specific individuals in these families is diminished.

Although child care remains the dominant component of informal care in terms of per capita time consumption, the prevalence of elder care is increasing due to the influx of "baby boomers" into the care market. Demographic transition processes that have been driving the decline in fertility and lifestyle changes have led to a modest decline in the propensity of spouses and adult children to provide care for older adults (Janus and Doty 2018). While the authors speculated that this shift may reflect the decreased availability of institutionalised care, it could also suggest that there has been a move away from an individual response to care needs, and towards a communal response, especially when care is needed for elderly people with cognitive impairments. As the extent to which individuals are prepared for such a shift is likely to vary across sub-populations for both economic and cultural reasons, the impact of this change on the health and well-being of caregivers may also be expected to differ.

There are a number of overarching cultural themes that transcend the boundaries of race, ethnicity, and national origin in a non-uniform manner. For instance, many Hispanic caregivers of elderly people with dementia are committed to providing their relatives with home-based care as part of their perceived normative responsibilities to family members (Neary and Mahoney 2005). This commitment is reflective of the broader spectrum of values that Hispanic/Latino cultural norms of familism and collectivism emphasise. These values engender social expectations on the part of care recipients, as well as culturally-induced compliance on the part of family caregivers (Padilla and Villalobos 2007). It is also important to note that whereas members of non-Hispanic white families tend to associate receiving care with a loss of independence, and thus often report having negative emotions when faced with the prospect of accepting care; family members of the Latino ethnic group in the U.S. tend to regard their caregiving duties as self-evident and morally unavoidable. In the U.S., the cultural value systems of both East Asian and Hispanic immigrant groups emphasise familism to a greater degree than the value systems of African Americans, and to a much larger extent than the value systems of white Americans (Knight and Sayegh 2010). In particular, the southeast Asian childrearing culture is often perceived by Americans as being familial, controlling, and overly nurturing (Morrow 1989). Indeed, preferences for familism and maintaining 
multigenerational households have been shown to permeate Indian, Chinese, and Japanese and other Asian cultures. In these societies, a general dependency on help and care from relatives is ingrained in the cultural fabric (Yunus 2005).

A comparison of child care arrangements among disadvantaged African American, Hispanic, and non-Hispanic white mothers revealed that Hispanic single mothers were more likely to rely on kin networks to meet their children's care needs, whereas single non-Hispanic white mothers were less likely to seek child care support from family members (Radey and Brewster 2007). Of the groups studied, married Hispanic mothers had by far the greatest reliance on maternal relatives for child care, while married non-Hispanic white mothers turned to paternal kin for child care support slightly more than the other two racial/ethnic groups. African Americans tended to have more cultural justifications for caregiving than whites, even though the likelihood of providing certain types of care, such as spousal care, differed between these two groups; with whites being slightly more likely to provide spousal care (Dilworth-Anderson et al. 2005).

While the values of familism and filial piety clearly play a role in patterns of caregiving across sub-populations, a qualitative study involving a wide spectrum of racial and ethnic minorities found that culturally-specific phenomena, such as group identity and barriers to service use, can also affect the extent to which different groups take advantage of care support options (Scharlach et al. 2006). The authors argued that language barriers and a lack of knowledge of available resources, which are especially common among first-generation immigrants, as well as mistrust of outside service providers and prejudice against their use, all reinforce the functional and cultural barriers to the utilisation of external help and resources by racial/ethnic minorities, while increasing their reliance on family or within-group care provision. However, when caregivers attempt to uphold cultural norms by avoiding reliance on formal and outside care support, they may find themselves in a precarious situation when they have full responsibility for providing care to elderly relatives with major impairments, such as dementia (Cox and Monk 1993).

Different life situations trigger different emotional responses, and caregiving is no exception. Generally, the existing research has shown that people tend to be happier and their overall life satisfaction improves when they are paying for goods and services that help them save time they otherwise would have to spend on routine tasks (Whillans et al. 2017). Thus, families with disposable income or savings may choose to outsource at least some of the care needs of family members. Having the option to outsource care can improve a caregiver's psychological and, by extension, physical health. However, the caregiver's appraisal of his/her burden largely depends on the orientation of his/her cultural values. It is, therefore, likely that a family care provider in an obligation-centred culture that emphasises filial piety will experience negative changes in health and well-being, whereas a family caregiver in a culture that focuses on familial support will experience improvements in health (Knight and Sayegh 2010).

As an illustrative example, Chinese caregivers for dementia patients tend to experience more strain than their American counterparts because cognitive impairment is stigmatised in the Chinese culture. Thus, to avoid exposure and/or because of 
lingual isolation, Chinese caregivers are more likely than American caregivers to attempt to provide care themselves, and to avoid seeking out formal care services and help from the community (Sun et al. 2012). By contrast, African American and Hispanic/Latino caregivers of any race tend to rely on collective effort, and therefore often have broader social support networks than white caregivers (Dilworth-Anderson et al. 2002). As a direct result of this orientation, African American and Hispanic/Latino informal care providers tend to report that their individual caregiver burden is relatively light, and that their life satisfaction has increased since taking on the caregiver role.

We therefore believe that exploring these differences in the caregiving patterns of various racial/ethnic and national groups will enable us to quantify the cumulative effect of cultural and family expectations on the amount of non-tangible resource production, regardless of its directionality vis-à-vis different generations and its daily incidence. The findings of this analysis could help to inform social policies in the U.S., where the population is ageing. This research is especially relevant given that the absolute effect sizes of various drivers of non-monetary transfers are far less documented than the market transfers and flows of capital that are registered in transnational and global projects, such as the National Transfer Accounts (Lee and Mason 2011) and the United Nations System of National Accounts.

To shed light on the personal and the economic consequences of the impact of cultural factors on informal care patterns in the United States, we formulate and test several hypotheses that could confirm and expand on evidence from prior research:

1. Women, on average, provide more care of all forms across all racial/ethnic groups and nationalities. This may appear to be an obvious assumption given that in every country, women provide most of the child care. However, the quantity of care women provide varies across racial, ethnic, and national background groups, as women who belong to different groups with unique attributes are exposed to socio-economic contexts that tend to either increase or reduce their involvement in informal care. Identifying the levels of commitment women have to caregiving in various cultural situations is essential for understanding the potential social and economic consequences of nonmonetary support in areas where certain cultural groups are prevalent.

2. Overall, we expect to find that non-Hispanic Asians and Hispanics of any race in the U.S., and first-generation immigrants in particular, to be more responsive to family care needs than other major racial/ethnic groups. These two groups are projected to follow divergent demographic growth paths in the future, because even though their mortality outcomes are similar, there is a sizeable gap in fertility between them. Members of both groups are increasingly likely to live in multigenerational households, and share an affinity for collective effort within the family. Examining how race/ethnicity and nativity affect informal care arrangements can help us disentangle the competing explanations for the effects of similar cultural propensities and contrasting demographic trends. 
3. Family income is inversely associated with the amount of time spent providing informal care. This follows from the assumption that care can be outsourced when disposable income is present. In one sense, household income can be thought of as the by-product of increased labour force participation, especially among women, who partially or fully substitute personally carrying out their child care duties with paid work, despite conflicting cultural demands. Alternatively, working-age adults who have spare income may prefer to hire formal services to care for their disabled and elderly dependents, especially if caring for their relatives offers them few emotional returns, while creating significant psychological and physical burdens. It is thus essential that we understand the role of family income in the allocation of caregiving tasks in different cultural and contextual settings.

4. Accounting for race, ethnicity, and national origin, in combination with demographic and socio-economic attributes and living arrangements, should be sufficient to allow us to isolate distinct patterns of informal care. If we assume that these factors capture the broad cultural characteristics of familism, communal support, filial piety and reciprocity, or individualism that are associated with cultures from different parts of the world, then only a minimal set of variables is needed to predict the likelihood and the intensity of intergenerational flows of time.

\section{Data}

In this study, we examine the effects of culturally proximal factors on caregiving patterns by building on our previous results and the methodology of non-monetary time transfers obtained from the American Time Use Survey (Dukhovnov and Zagheni 2015). We disaggregate the matrices of time transfers by age and sex in terms of racial/ethnic belonging and national origin groups. To measure the flows of time from and to different age/sex groups, we analyse child care and adult care activities as part of household production.

The American Time Use Survey (ATUS) is a cross-sectional, nationally representative survey of Americans aged 15 and older. It is conducted annually by the U.S. Bureau of Labor Statistics, which draws the sample from participants who completed all waves of the Current Population Survey. The purpose of the ATUS is to capture in a diary form how Americans spend their time. The participants are required to maintain detailed records of their personal activities, including information for each activity on the time of day, duration, location, and people present. The response rates have been declining in recent years, but are close to the 50 per cent mark, thus yielding an annual sample of about 12,000 observations. The advantage of the ATUS over other non-diary-based studies is that the care flows captured are not restricted by relationship categories of caregivers or care recipients. Thus, using ATUS data, it is possible to explore some of the less common care arrangements that different ethnic and cultural groups may engage in. The main 
questionnaire provides variables detailing the respondents' age, sex, race, ethnicity, national origin by country, citizenship status, family income, level of education, and employment status. It also includes variables on other basic personal and household characteristics, including for individuals outside of the respondents' immediate household. To ensure adequate representation of transfers across racial, ethnic, and national minorities, we combine samples of the five consecutive years of data, from 2011 through 2015.

\section{Method}

As part of a series of papers on non-monetary intergenerational transfers, we have developed a set of numerical matrices that characterise the mean flow of care time; in its most basic form by the age and the sex of the caregivers and the care recipients, and further disaggregated by race and ethnicity. We consider two types of care that are unpaid and that are not part of a respondent's professional activities: child care and adult care. The economic and psychological burdens associated with each of these types of care are theoretically distinct. Hence, the two forms are computed separately prior to their concatenation in a matrix. For the present analysis, only transfers that took place between the caregiver respondents and the care recipients within their household were considered for the construction of matrices. Non-household transfers - i.e. transfers between caregiving respondents and care recipients who were not sharing a household - cannot be estimated directly or with a high degree of certainty, since most potential care recipients living outside of the respondents' household were not assigned even the most basic demographic attributes in the ATUS, such as age, sex, or race. Another important methodological point is that the matrices reflect caregiving patterns conditional on positive caregiving status. This allows for a more intuitive visual group comparison of caregiving intensity. Importantly, beyond providing a visualisation of these patterns, we use for the remainder of the analysis matrices that represent transfers as national averages, regardless of the caregiving status.

The analysis proceeds in three stages. First, we map the mean daily amount of care time transferred by the members of various age, sex, and racial/ethnic groups who indicated in the course of the interview that they had participated in at least one care activity. To map these transfers, we create a set of matrices for caregivers by aggregating the time spent on each type of care activity (i.e. child care and adult care) by age and sex for every major racial/ethnic group in the United States. For example, if during a child care activity lasting 10 minutes one child under age 18 was present, that child - whose age and sex are known - will be considered the recipient of the 10 minutes of care. If, however, multiple children were present during the activity, the 10 minutes of care are split between all of the children equally. An analogous allocation procedure is followed for adult care before all of the values are weighted and aggregated into matrices for each race/ethnicity by the age and the sex of the caregivers and of the "implied" care recipients. We calculate, but do not show, a 
similar set of matrices for respondents by national origin, since the vast majority of the caregivers were born in the United States. Providing the estimated values for foreign-born residents would lead to sparsity with many missing values within a matrix, and would thus produce uninterpretable results based on the low cell counts in the immigrant-linked set of matrices. These matrices will nevertheless be further summarised in the profiles of informal care time production and consumption by age that represent marginal sums for each racial/ethnic and national origin group.

Next, we attempt to explain the care patterns by running a set of logistic models to estimate the odds of providing each form of care. We then run an analogous set of hierarchical ordinary least squares (OLS) models to estimate the average amount of time in minutes per day that members of demographic sub-groups spend on care activities relative to the reference group. Due to the highly skewed distribution of values of care time per day, the outcome variable is log-transformed for the OLS models. In addition to demographic, racial/ethnic, and national background attributes, we consider a number of socio-economic predictors: namely, family income, number of adults and own children under age 18 in the household, employment status, decade of immigrant entry to the U.S., presence of a spouse or partner, level of education, and current school enrolment. These variables were chosen to represent socio-economic status, potential social support structure, and non-care time commitments; and to approximate the relative cultural assimilation of immigrant respondents. Moreover, these variables uniquely describe individual characteristics without inducing collinearity. ${ }^{1}$ For the purpose of modelling the impact of general characteristics, we treat nationality (nativity) using seven broad regional groups of countries: namely, the U.S. and Canada, Europe, West/Central Asia, East Asia, South and Central America including Mexico, Africa, and Australia and New Zealand. East and West/Central Asia are demarcated by the western borders of China, Myanmar, Thailand, and Indonesia in order to broadly represent a contingent of countries with a majority or a substantial Muslim population. Such broad groups obviously overlook finer cultural differences (e.g. between Mexicans and Cubans). However, based on a review of the past literature, we expect to find that the effects on both the intensity and the prevalence of care of broad cultural values, such as familism, filial piety, individualism, and collectivism, transcend national boundaries. We therefore believe that the classification of nativity by wide regional groups should be sufficient to explain the overall propensity of individuals to engage in various forms of non-market activities.

The main purpose of the logistic models is to show the overall probability of providing any amount of child care, adult care, or one or the other. For each form, we run a pair of logistic models. The first is a fully specified model with interactions by sex and race/ethnicity, sex and nativity, as well as sex and decade

\footnotetext{
1 As per Fox and Monette (1992), the version of generalised-variance inflation factors (GVIF) method is comparable across multidimensional categorical factors, with $G V I F^{1 / 2 d f}<2$, indicating only a weak factor association, except for continuous correlated age and age-squared.
} 
of immigration. The second model excludes race and ethnicity, as well as nativity factors and the respective interactions. Thus, our aim in running these models is to test the effects of cultural proxy variables on the probability of providing various types of informal care.

After we have identified the group propensities to engage in care, the OLS estimation aims to shed light on the factors that affect the intensity of this care. We run a series of six nested models beginning with the simplest specification, which includes age (transformed to represent the minimum of 15 years at baseline), age-squared, and sex. We then gradually add race/ethnicity, nativity, and decade of immigration with race/ethnicity and nativity interactions by sex (model 2). In the OLS model 3, we add interactions of decade of immigration by sex to evaluate its effect on the two cultural proxies we test. In model 4, we add socio-economic variables, such as school enrolment, family income, work status, and work time commitment. Finally, in model 5, we add social support and household structure variables, such as the presence of a spouse, children, and other adults in the household. As in the case of the logistic model comparisons, the OLS model 6 is added at the end to test the effects of race/ethnicity and nativity in the fullyspecified model through their exclusion. We run an analogous set of models for adult care.

Finally, we present the care support ratio (CSR) as an application of the results we obtain over the previous steps. We discuss the methodological details and the computation of this measure in the dedicated sub-section of the results. As we explain later, the CSR is a useful measure of non-market transfers designed to complement the macro-scale economic indicators of surplus and deficit of value of goods produced or consumed. In this case, we consider the availability of informal care time.

\section{Results}

\subsection{Informal care time transfers}

Early child care, typically administered by parents and grandparents, is the most salient type of informal care. As indicated by the hotspots representing transfers to children aged 14 and under in Figure 1, the average amount of time committed to child care activities among the U.S. caregivers is about two hours per transfer day. Spousal care is another typical form of care. In Figure 1, spousal care is indicated by the diagonal patterns between the matrices of transfers between opposite sexes. The time spent on spousal care by caregivers peaks at older ages, when the average caregiver spends slightly more than an hour per day caring for his/her significant other. This set of matrices has been decomposed into several sets to additionally show the patterns of time flows by race and ethnicity. The decomposed matrices describing these patterns of care time transfers by age, sex, and race/ethnicity are shown in Figure A.1 in a simplified format. Among the caregiving parents, Asians 
Figure 1:

Mean national daily care time transfer matrices in $\log _{10}$ minutes by age and sex for transfers from caregivers to care recipients, conditional on providing care

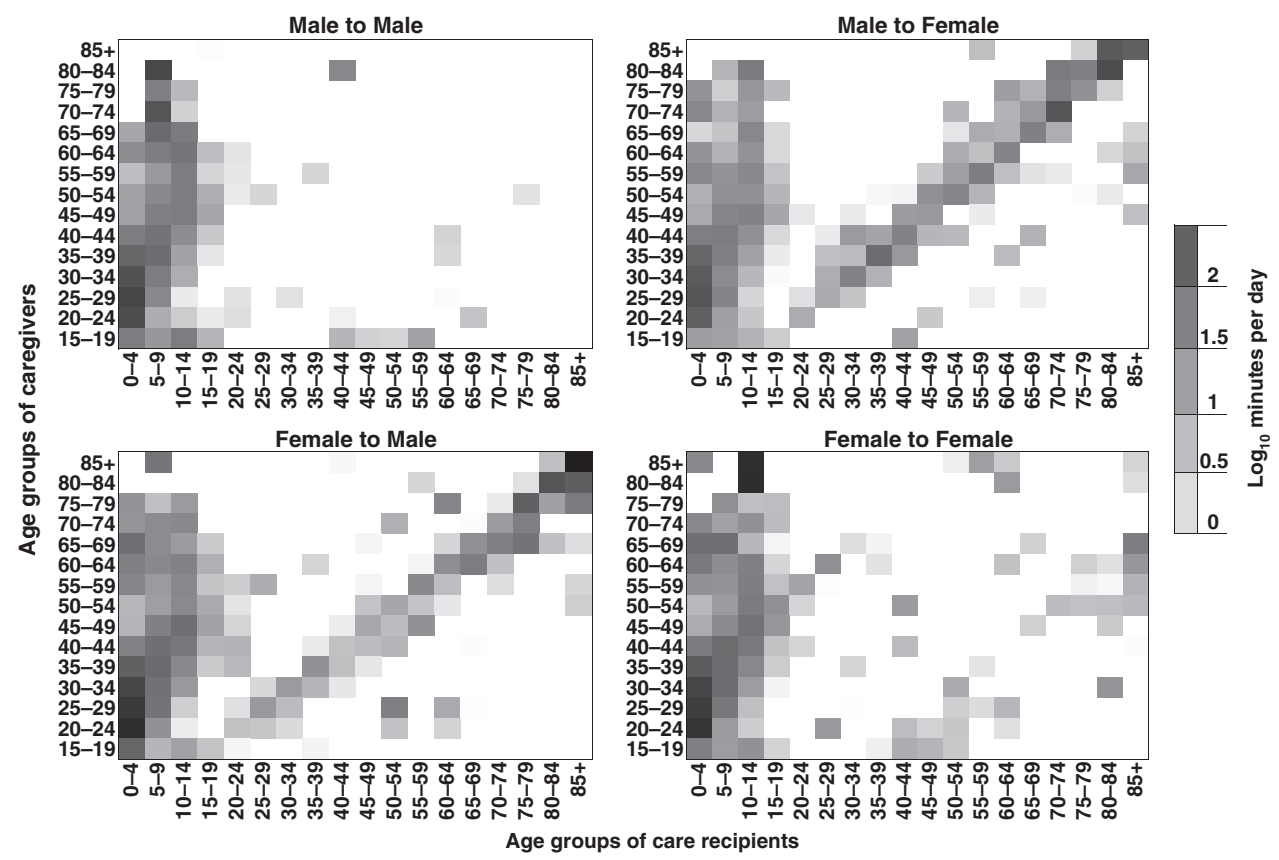

Note: Values below one minute per day are masked to add visual clarity.

spend the most time caring for their children - peaking at over two hours per day, on average - followed by Hispanics of any race, and by non-Hispanic whites and African Americans. Grandparental care is another prevalent form of caregiving for all racial/ethnic categories, although it is quite concentrated within same-sex transfers. Spousal care is very prevalent among white caregivers, and among older adults in particular. This pattern is shown in Figure 1 as a consistent diagonal trend. Among African Americans, spousal care is equally prevalent, but with greater variation in the ages of spouses. Among Asians - more so than among the caregivers of other racial categories - the prevalence of spousal care seems to intensify during the childbearing ages.

The decomposition of the national results by age, sex, race/ethnicity, and national origin offers some interesting insights into the levels of intensity and engagement in child care and adult care. Table 1 shows the average daily rates of participation in child care and adult care activities by race/ethnicity and broad national origin groups. Unfortunately, the ATUS methodology has no provisions that would allow for the calculation of the general prevalence, but states that it is likely to be higher than the daily rates. As expected, we observe that both child care participation rates and 
Table 1:

Daily household informal care participation rates and mean care time commitment by race/ethnicity and nativity groups, by care type and the period total fertility rate

\begin{tabular}{|c|c|c|c|c|}
\hline Place of birth & $\begin{array}{c}\text { Non-Hispanic } \\
\text { white }\end{array}$ & $\begin{array}{c}\text { Non-Hispanic } \\
\text { black }\end{array}$ & $\begin{array}{c}\text { Non-Hispanic } \\
\text { Asian }\end{array}$ & $\begin{array}{c}\text { Hispanic, } \\
\text { any race }\end{array}$ \\
\hline & \multicolumn{4}{|c|}{ Daily participation rates } \\
\hline U.S. \& Canada & 0.178 & 0.157 & 0.165 & 0.214 \\
\hline Europe & 0.195 & 0.290 & $0.196^{\dagger}$ & $0.092^{\dagger}$ \\
\hline Asia & 0.246 & $0.208^{\dagger}$ & 0.294 & $0.256^{\dagger}$ \\
\hline Latin America \& Mexico & 0.314 & 0.199 & 0.234 & 0.314 \\
\hline Africa & 0.308 & 0.315 & $0.193^{\dagger}$ & $0^{\dagger}$ \\
\hline Australia \& New Zealand & 0.450 & - & $0^{\dagger}$ & - \\
\hline & \multicolumn{4}{|c|}{ Adult care } \\
\hline U.S. \& Canada & 0.042 & 0.042 & 0.036 & 0.057 \\
\hline Europe & 0.035 & $0^{\dagger}$ & $0^{\dagger}$ & $0.043^{\dagger}$ \\
\hline Asia & 0.079 & $0.122^{\dagger}$ & 0.033 & $0.020^{\dagger}$ \\
\hline Latin America \& Mexico & $0.073^{\dagger}$ & 0.048 & $0.232^{\dagger}$ & 0.035 \\
\hline Africa & $0.044^{\dagger}$ & $0.033^{\dagger}$ & - & $0.731^{\dagger}$ \\
\hline \multirow[t]{2}{*}{ Australia \& New Zealand } & $0.075^{\dagger}$ & - & $0^{\dagger}$ & - \\
\hline & \multicolumn{4}{|c|}{ Mean time production in minutes per day } \\
\hline U.S. \& Canada & 25.7 & 20.4 & 21.2 & 29.8 \\
\hline Europe & 29.3 & 29.7 & $26.9^{\dagger}$ & $10.1^{\dagger}$ \\
\hline Asia & 41.7 & $20.9^{\dagger}$ & 44.4 & $20.2^{\dagger}$ \\
\hline Latin America \& Mexico & 47.8 & 29.1 & 37.6 & 46.3 \\
\hline Africa & 46.8 & 39.0 & $54.7^{\dagger}$ & $0^{\dagger}$ \\
\hline \multirow[t]{2}{*}{ Australia \& New Zealand } & 92.8 & - & $0^{\dagger}$ & - \\
\hline & \multicolumn{4}{|c|}{ Adult care } \\
\hline U.S. \& Canada & 3.1 & 3.1 & 2.4 & 3.9 \\
\hline Europe & 3.7 & $0^{\dagger}$ & $0^{\dagger}$ & $6.1^{\dagger}$ \\
\hline Asia & 7.7 & $9.9^{\dagger}$ & 2.3 & $0.2^{\dagger}$ \\
\hline Latin America \& Mexico & $8.5^{\dagger}$ & 4.7 & $13.9^{\dagger}$ & 3.3 \\
\hline Africa & $2.7^{\dagger}$ & $4.6^{\dagger}$ & - & $65.7^{\dagger}$ \\
\hline Australia \& New Zealand & $4.6^{\dagger}$ & - & $0^{\dagger}$ & - \\
\hline Total Fertility Rate (TFR) $)^{\S}$ & 1.72 & 1.83 & 1.69 & 2.09 \\
\hline
\end{tabular}

Note: ${ }^{\dagger}$ indicates $\mathrm{N}<10$.

Source: ${ }^{\S}$ NVSS (31 January 2018). "Birth rates, by age of mother: United States, 2010-2016, and by age and race and Hispanic origin of mother, 2016”. National Vital Statistics Reports 67(1), p.18. 
intensity levels are substantially greater for foreign-born individuals across the four racial/ethnic categories. Only around 16-18 per cent of native-born and Canadianborn Americans are caregivers for their children, with a slightly higher share among the Hispanic sub-population (21.4 per cent). For the foreign-born Hispanics, the participation rate is 46.7 per cent higher than it is for their native-born counterparts. This is not too surprising, given that the number of children in the average Hispanic immigrant family is higher than the number of children in the average U.S.- or Canadian-born Hispanic family. Yet this relationship does not hold for Australian and New Zealander immigrants, among whom the child care participation rate and the average child care intensity are 2.5 and 3.6 times greater, respectively, than they are in native-born whites, even though the period total fertility rates (TFR) of Australians and New Zealanders are comparable to the TFR of American-born whites (i.e. in 1.72-1.87 range). However, this result should be interpreted with extreme caution, as the five-year sample for the Australia and New Zealand group is very small, as Table A.1 shows. Similarly, African- and Latin American-born nonHispanic whites are found to be about 75 per cent more likely to provide child care than native-born whites. As expected, foreign-born Asian Americans are 1.78 times more likely to be the primary caregivers for their children than native-born Asians, with 29.4 per cent of those born in Asia providing child care on a typical day. By contrast, African Americans have the lowest child care participation rate of all racial/ethnic and national origin groups, with only around 15.7 per cent providing care for their children. Meanwhile, their foreign-born counterparts from Africa and Latin America have child care participation rates that are on par with those of other foreign-born groups.

For adult care, trends in participation rates and intensities do not vary nearly as much between native and foreign-born groups. The adult care patterns do not differ greatly between native-born groups, as at least 3.6-5.7 per cent of Americans provide adult care on a daily basis. Interestingly, native-born Hispanics are more likely than their foreign-born counterparts to provide adult care. However, the national average adult care intensity among all racial/ethnic and national origin categories is low, on an order of magnitude of less than 10 minutes per day. Of all coefficients that could be interpreted with a fair amount of certainty, the intensity for non-Hispanic whites born in Asia is the highest, at 7.7 minutes of adult care per day. In relative terms, this result aligns with the findings of the literature on informal care traditions by national origin, which has shown that familial duties toward parental and elder generations are emphasised in this group.

By summarising the findings in the form of marginal profiles by race/ethnicity derived from the respective national mean care transfers matrices, Figure 2 allows us to easily observe not only the age pattern of production of informal care time across the life course, but the stages of life at which the greatest amounts of care are received. The youngest children, ages $0-4$, are the primary recipients of informal care time, receiving just over five hours of care on average from their white, Asian, and Hispanic caregivers. In stark contrast, young African American children receive on average about two hours less care per day than the other groups. This outcome is 
Figure 2:

Profiles of mean daily care time, household production, consumption, and non-household production by race and ethnicity
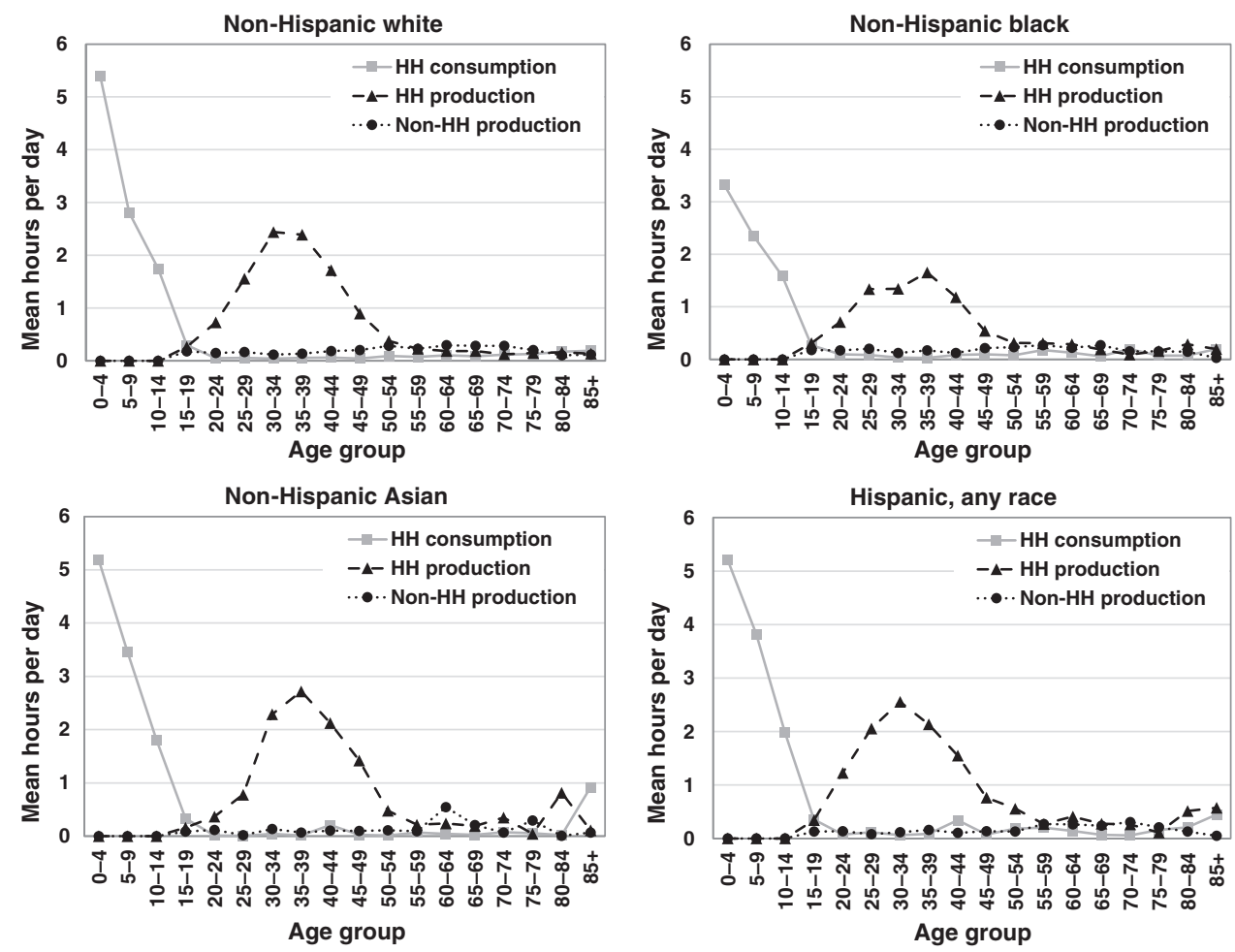

consistent with the results of Table 1, which shows that the low consumption of time corresponds to the low production of time. Second, the characteristic hump in the working-age range reflects the peak in the average care time production, and is thus akin to the surplus economic value produced by the working-age population. Given the rather subdued pattern of production and consumption of household informal care at all other ages, it is not difficult to see that the lion's share of all transfers made by working-age parents and other adults within a household are allocated to early child care.

Indeed, such macro patterns exist predominantly within a caregiver's household. The amount of time caregivers spend on non-household production, included for comparison, is small, and is spread thinly across all adult ages, peaking at about 20 minutes per day on average around early retirement. The need for this type of production mainly arises when caregivers have multiple, and occasionally simultaneous, responsibilities to provide care for a spouse/partner and grandchildren. Because of a lack of information on healthy non-household adult care recipients, care 
consumption by younger adults is not well understood. It may, however, be assumed that such transfers are relatively rare, and involve low intensities of caregiver time commitment.

Next, we take a closer look at the effect of the presence of potential care recipients on the average intensity of informal care flows. Figure 3 presents the matrix marginal profiles by race/ethnicity of the average amounts of household care time production and consumption and non-household production; conditional on the presence of children under age 18 in the household and potential spousal support. The two principal features of these profiles are immediately apparent. First, the amount of time spent on child care increases, as consumption doubles relative to the overall average for the youngest group among all racial groups except Hispanics, among whom the increase is somewhat modest. A possible explanation for this pattern is that Hispanic families have more children on average than other racial/ethnic groups, which could lead to reduced per capita care support when the care demands are greatest and the production flows are split among multiple children. However, as soon as children reach the ages of 5-9 and 10-14, the gap between the racial/ethnic groups narrows. When we look at the production of child care, we see that, conditional on the presence of children in the household, grandparenting patterns become quite distinctive. It appears that African Americans and Hispanics rely on household grandparental care for two generations of children, as two smaller care production peaks of about 1-1.5 hours at ages 60-64 and 75-84 are observed; although it is possible that a small portion of this time is spent on spousal care. Among non-Hispanic whites, some grandparental child care is also provided. However, the finding that the production of grandparental child care is uniformly distributed across pre- and post-retirement ages in this highly heterogeneous population suggests that childbearing ages vary considerably among white Americans. By contrast, among non-Hispanic Asians, the range of ages at which care is given and received tends to be much narrower. However, this observation implies that in this group, the level of care commitment at those ages tends to be relatively intensive and concentrated around child care and spousal care during the childbearing years, as the matrices in Figure A.2 show. This pattern could be the result of a group-specific cultural/normative trait, or an artefact of the sparse sample. When we look at adult care consumption conditioned on the presence of a spouse or unmarried partner, no racial/ethnic group stands out. The average level of consumption is generally no more than half an hour per day, and does not intensify until people reach very old age, when a partner's frailty may oblige the other partner to provide care support. The finding that this pattern is more common among Hispanics and Asians - and, albeit to a lesser extent, among whites - than among African Americans may be attributable to these groups having greater longevity, and thus being more likely than African Americans to experience degenerative health conditions associated with old age. 
Figure 3:

Profiles of mean daily care time in hours, household production, consumption, and non-household production by race/ethnicity; conditional on the presence of household children (left column) and a spouse or unmarried partner (right column)
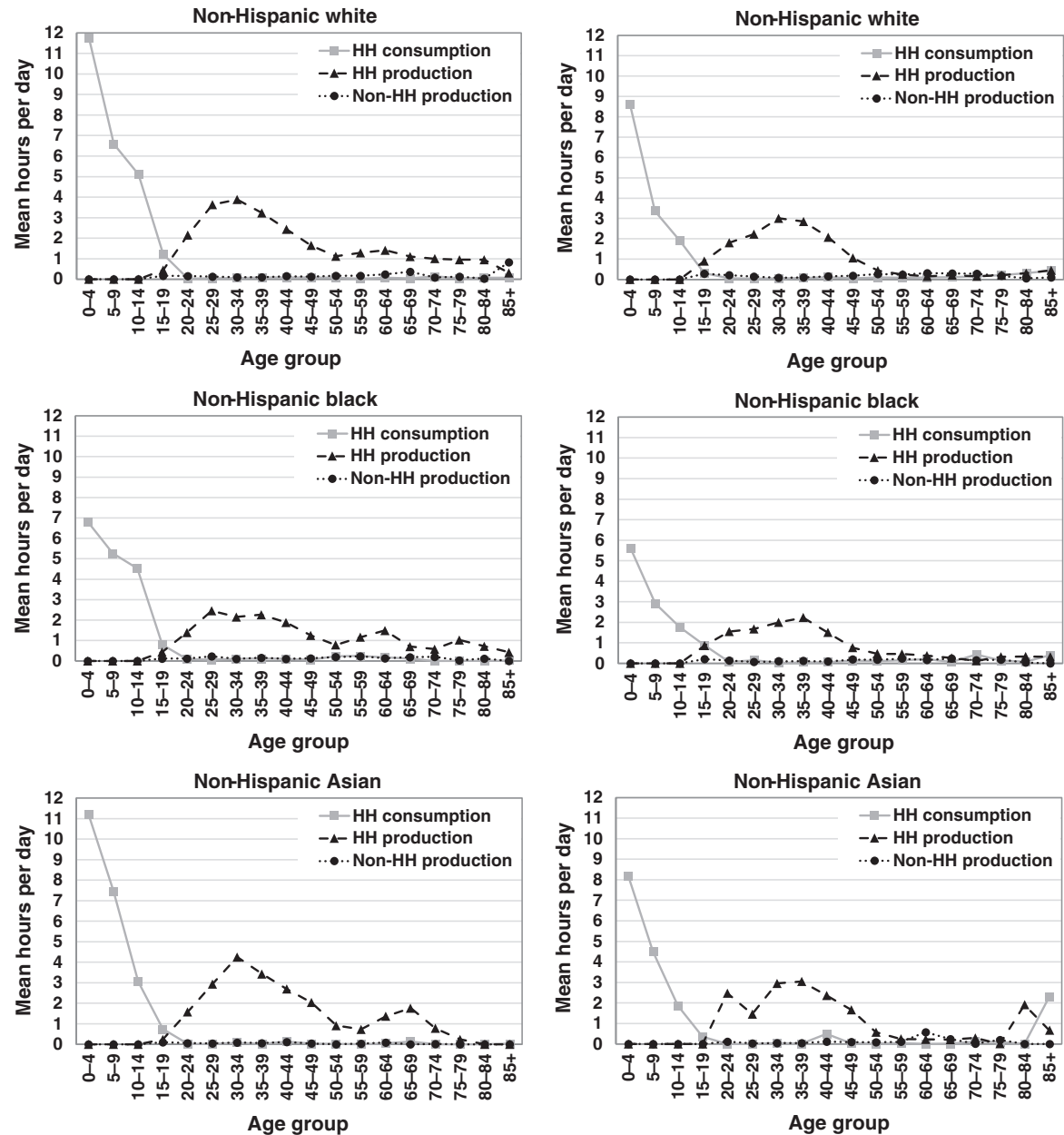

Age group
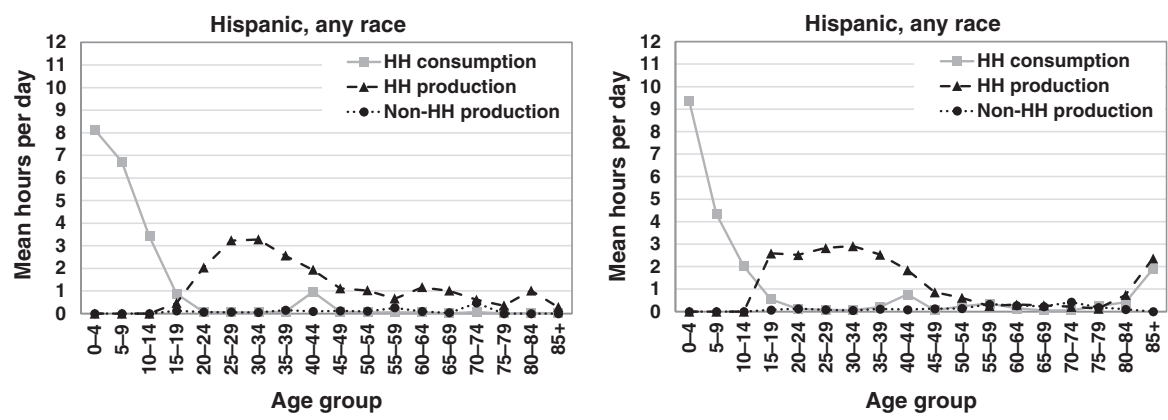


\subsection{Models of informal care prevalence and intensity}

In this section, we evaluate the effects of race/ethnicity and nativity as cultural proxy variables on the probability of engaging in informal care activities on an average day. Table 2 presents the results of a set of logistic models that predict the log odds of providing household care in general, child care, and adult care. The odd-numbered models are fully specified, and are compared to the even-numbered complements that exclude the effects of race/ethnicity and nativity on the chances of providing the two forms of care. The overall model 1 significantly predicts that relative to women, Asian and Hispanic men have 57 per cent lower odds of providing care and African American men have 68 per cent lower odds of providing care. While this effect is largely sustained for both child care models, no significant difference is found between men and women in the propensity to provide adult care; except in the Central Asian group, among whom men have 42 per cent lower odds than women of providing adult care. These patterns are displayed in matrices in Figure A.1. Looking at these patterns, it becomes clear that focusing on the main effects of national origin offers no additional insights for U.S.- and Canadian-born child care providers. We can, however, see crossover interaction effects, which suggests that there is a significantly larger gap in the odds of care participation between men and women born in African and Latin American countries and Mexico. This finding may be related to the strong cultural tradition in these countries of dividing up household labour by gender, with women doing more of the child care and men being more likely to work outside of the home. As expected, we find that household structure, and the presence of a spouse or partner in particular, contributes a great deal to the fit of all three pairs of models. The effect of household structure is quite profound, especially on adult care, for which the odds of participation are increased 5.1 times relative to the baseline. This result supports the supposition that a substantial proportion of adult care transfers within a household are associated with spousal care. Age and socio-economic effects are significant in predictable ways for the overall and the child care models. For instance, in the child care model, age increases the odds of providing care by 20.1 per cent curvilinearly for every year over the baseline. The odds then decrease by one per cent with increasing age, as child care responsibilities diminish after the childbearing years. For adult care, the odds decrease significantly with age, by 4.9 per cent; which may suggest that upward adult care transfers are more prevalent (e.g. that adult children tend to provide care for their elderly parents, while older people are less likely to provide care for a spouse or sibling). For all logistic models, most socio-economic and household structural factors significantly predict that the odds of providing care are higher among those who are more educated, have stronger social support (that is, those who share a household with a spouse or partner or other adults), and who are unemployed or work relatively few hours. At the same time, family income is positively associated with child care participation and negatively associated with adult care. This pattern is foreseeable, as given the physical and emotional burdens that adult care imposes on caregivers, family members may prefer outsourcing 
Table 2:

Log odds of providing various forms of household informal care

\begin{tabular}{|c|c|c|c|c|c|c|}
\hline & \multicolumn{2}{|c|}{ Overall } & \multicolumn{2}{|c|}{ Child care } & \multicolumn{2}{|c|}{ Adult care } \\
\hline & (1) & (2) & (3) & (4) & (5) & (6) \\
\hline (Intercept) & $-3.31^{* * *}$ & $-3.38^{* * *}$ & $-3.49^{* * *}$ & $-3.59^{* * *}$ & $-4.44^{* * *}$ & $-4.42^{* * *}$ \\
\hline Age & $0.17^{* * *}$ & $0.17^{* * *}$ & $0.19^{* * *}$ & $0.19^{* * *}$ & $-0.05^{* *}$ & $-0.05^{* *}$ \\
\hline Age squared & $-0.01^{* * *}$ & $-0.01^{* * *}$ & $-0.01^{* * *}$ & $-0.01^{* * *}$ & $0^{* *}$ & $0^{* *}$ \\
\hline \multicolumn{7}{|l|}{ Sex (female ref.) } \\
\hline Male & $-0.85^{* * *}$ & $-0.88^{* * *}$ & $-0.92^{* * *}$ & $-0.96^{* * *}$ & -0.04 & -0.04 \\
\hline \multicolumn{7}{|l|}{$\begin{array}{l}\text { Race/ethnicity } \\
\quad \text { (non-Hispanic white ref.) }\end{array}$} \\
\hline Non-Hispanic black & $-0.21^{* * *}$ & & $-0.25^{* * *}$ & & 0.15 & \\
\hline Non-Hispanic Asian & -0.17 & & -0.15 & & -0.38 & \\
\hline Hispanic of any race & $-0.14^{*}$ & & $-0.17^{*}$ & & 0.09 & \\
\hline \multicolumn{7}{|l|}{ Nativity (U.S./Canada ref.) } \\
\hline Born in Europe & 0.03 & & 0.12 & & 0.42 & \\
\hline Born in West/Central Asia & 0.25 & & 0.19 & & $1.02^{*}$ & \\
\hline Born in East Asia & 0.05 & & 0.11 & & 0.22 & \\
\hline $\begin{array}{l}\text { Born in Latin America } \\
\text { or Mexico }\end{array}$ & 0.20 & & 0.30 & & -0.08 & \\
\hline Born in Africa & 0.20 & & 0.33 & & -0.24 & \\
\hline $\begin{array}{l}\text { Born in Australia } \\
\text { or New Zealand }\end{array}$ & -0.21 & & -0.15 & & 2.30 & \\
\hline \multicolumn{7}{|l|}{$\begin{array}{l}\text { Decade of immigration } \\
\text { (native-born ref.) }\end{array}$} \\
\hline Prior to 1950 & - & - & - & - & - & - \\
\hline $1950-1959$ & 7.27 & 7.21 & 7.13 & 7.17 & -7.68 & -7.90 \\
\hline 1960-1969 & 0.05 & 0.10 & -0.10 & 0.02 & 0.12 & 0.32 \\
\hline 1970-1979 & -0.22 & -0.18 & -0.33 & -0.22 & -0.09 & 0.22 \\
\hline 1980-1989 & -0.13 & -0.05 & -0.18 & -0.03 & -0.07 & -0.06 \\
\hline 1990-1999 & -0.14 & -0.05 & -0.19 & -0.03 & -0.42 & -0.30 \\
\hline 2000 onward & -0.06 & 0.03 & -0.09 & 0.06 & -0.51 & $-0.32^{*}$ \\
\hline $\begin{array}{l}\text { Family income } \\
\qquad(\$ 25,000 \text { increments })\end{array}$ & 0.01 & $0.03^{*}$ & $0.03^{*}$ & $0.04^{* * *}$ & $-0.06^{*}$ & $-0.06^{* *}$ \\
\hline \multicolumn{7}{|l|}{$\begin{array}{l}\text { Educational attainment } \\
\text { (<high school ref.) }\end{array}$} \\
\hline High school & $0.59^{* * *}$ & $0.62^{* * *}$ & $0.66^{* * *}$ & $0.68^{* * *}$ & 0.03 & 0.08 \\
\hline Some college/college & $0.85^{* * *}$ & $0.90^{* * *}$ & $0.91^{* * *}$ & $0.96^{* * *}$ & 0.22 & $0.27^{*}$ \\
\hline Professional/Ph.D. & $1.06^{* * *}$ & $1.12^{* * *}$ & $1.12^{* * *}$ & $1.19^{* * *}$ & 0.27 & $0.32^{*}$ \\
\hline
\end{tabular}

\section{Continued}


Table 2:

Continued

\begin{tabular}{|c|c|c|c|c|c|c|}
\hline & \multicolumn{2}{|c|}{ Overall } & \multicolumn{2}{|c|}{ Child care } & \multicolumn{2}{|c|}{ Adult care } \\
\hline & (1) & (2) & (3) & (4) & (5) & (6) \\
\hline \multicolumn{7}{|l|}{$\begin{array}{l}\text { School enrolment } \\
\text { (not in school ref.) }\end{array}$} \\
\hline Enrolled & $-0.41^{* * *}$ & $-0.42^{* * *}$ & $-0.44^{* * *}$ & $-0.46^{* * *}$ & -0.05 & -0.03 \\
\hline \multicolumn{7}{|l|}{$\begin{array}{l}\text { Employment status } \\
\text { (employed ref.) }\end{array}$} \\
\hline Unemployed & $0.35^{* * *}$ & $0.33^{* * *}$ & $0.33^{* * *}$ & $0.31^{* * * *}$ & $0.24^{*}$ & $0.26^{*}$ \\
\hline Not in labour force & $0.34^{* * *}$ & $0.34^{* * *}$ & $0.32^{* * *}$ & $0.33^{* * *}$ & 0.15 & 0.15 \\
\hline Hours spent working & $-0.02^{* * *}$ & $-0.02^{* * *}$ & $-0.02^{* * *}$ & $-0.02^{* * *}$ & $-0.04^{* * *}$ & $-0.04^{* * *}$ \\
\hline $\begin{array}{l}\text { Presence of spouse } \\
\text { or partner }\end{array}$ & $0.84^{* * *}$ & $0.86^{* * *}$ & $0.72^{* * *}$ & $0.74^{* * *}$ & $1.63^{* * *}$ & $1.59^{* * *}$ \\
\hline $\begin{array}{l}\text { Num. of } \mathrm{HH} \text { children } \\
\text { under } 18\end{array}$ & $1.01^{* * *}$ & $1.01^{* * *}$ & $1.11^{* * *}$ & $1.11^{* * *}$ & $-0.06^{*}$ & -0.04 \\
\hline Num. of other $\mathrm{HH}$ adults & $-0.16^{* * *}$ & $-0.17^{* * *}$ & $-0.32^{* * *}$ & $-0.32^{* * *}$ & $0.47^{* * *}$ & $0.47^{* * *}$ \\
\hline \multicolumn{7}{|l|}{ Interactions } \\
\hline $\begin{array}{l}\text { Male } \times \text { Non-Hispanic } \\
\text { black }\end{array}$ & $-0.28^{* * *}$ & & $-0.30^{* *}$ & & -0.21 & \\
\hline $\begin{array}{l}\text { Male } \times \text { Non-Hispanic } \\
\text { Asian }\end{array}$ & 0.22 & & 0.26 & & 0.23 & \\
\hline $\begin{array}{l}\text { Male } \times \text { Hispanic of } \\
\text { any race }\end{array}$ & -0.18 & & $-0.31^{* *}$ & & 0.21 & \\
\hline Male $\times$ Born in Europe & -0.35 & & -0.50 & & -1.17 & \\
\hline $\begin{array}{l}\text { Male } \times \text { Born in West } / \\
\text { Central Asia }\end{array}$ & -0.51 & & -0.57 & & $-1.56^{*}$ & \\
\hline Male $\times$ Born in East Asia & -0.19 & & -0.46 & & 0.14 & \\
\hline $\begin{array}{l}\text { Male } \times \text { Born in Latin } \\
\text { America or Mexico }\end{array}$ & -0.63 & & $-0.76^{*}$ & & -0.50 & \\
\hline Male $\times$ Born in Africa & -0.45 & & $-0.87^{*}$ & & 0.77 & \\
\hline $\begin{array}{l}\text { Male } \times \text { Born in Australia } \\
\text { or New Zealand }\end{array}$ & 0.78 & & 0.69 & & -1.35 & \\
\hline $\begin{array}{l}\text { Male } \times \text { Immigrated } \\
\text { prior to } 1950\end{array}$ & - & - & - & - & - & - \\
\hline $\begin{array}{l}\text { Male } \times \text { Immigrated } \\
\text { in } 1950-1959\end{array}$ & - & - & - & - & - & - \\
\hline $\begin{array}{l}\text { Male } \times \text { Immigrated } \\
\quad \text { in } 1960-1969\end{array}$ & 0.29 & 0.19 & 0.78 & 0.50 & -0.39 & -0.98 \\
\hline $\begin{array}{l}\text { Male } \times \text { Immigrated } \\
\text { in } 1970-1979\end{array}$ & 0.55 & 0.10 & $0.90^{*}$ & 0.25 & 0.11 & -0.45 \\
\hline $\begin{array}{l}\text { Male } \times \text { Immigrated } \\
\text { in } 1980-1989\end{array}$ & 0.54 & 0.09 & $0.85^{*}$ & 0.17 & -0.52 & -0.66 \\
\hline
\end{tabular}

\section{Continued}


Table 2:

\section{Continued}

\begin{tabular}{|c|c|c|c|c|c|c|}
\hline & \multicolumn{2}{|c|}{ Overall } & \multicolumn{2}{|c|}{ Child care } & \multicolumn{2}{|c|}{ Adult care } \\
\hline & (1) & (2) & (3) & (4) & (5) & (6) \\
\hline $\begin{array}{l}\text { Male } \times \text { Immigrated } \\
\text { in 1990-1999 }\end{array}$ & 0.41 & -0.14 & 0.58 & -0.17 & 0.86 & 0.47 \\
\hline $\begin{array}{l}\text { Male } \times \text { Immigrated } \\
\text { in } 2000 \text { onward }\end{array}$ & 0.40 & -0.10 & 0.53 & -0.17 & 0.83 & 0.43 \\
\hline $\begin{array}{l}\text { Hosmer-Lemeshow GOF } \\
\quad \text { test }(\mathrm{df}=8)\end{array}$ & $579.95^{* * *}$ & $647.43^{* * *}$ & $814.76^{* * *}$ & $896.06^{* * *}$ & $66.28^{* * *}$ & $67.46^{* * *}$ \\
\hline AIC & 28919 & 29610 & 27354 & 28027 & 9963.5 & 10244 \\
\hline $\begin{array}{l}\text { Likelihood ratio test } \\
\quad(\mathrm{df}=18)\end{array}$ & \multicolumn{2}{|c|}{$86.041^{* * *}$} & \multicolumn{2}{|c|}{$113.425^{* * *}$} & \multicolumn{2}{|c|}{$35.550^{* *}$} \\
\hline
\end{tabular}

Note: ${ }^{* * *} p<0.001,{ }^{* *} p<0.01,{ }^{*} p<0.05$.

their care work to performing it themselves. The intensity of such transfers must also be considered. Of key importance to the logistic models is the evaluation of the contributions of race/ethnicity and nativity to the fit of all of the models. All three models demonstrate practical insensitivity to the exclusion of race/ethnicity or nativity. The overall fit of all of the models is rather poor, even if the likelihood ratio test and the Hosmer-Lemeshow goodness of fit statistic indicate that the changes in the fit are statistically significant when race/ethnicity and nativity are included.

The hierarchical OLS models for the intensity of child care and adult care are presented in Tables 3(a) and 3(b), respectively. Compared to non-Hispanic whites, African Americans consistently spend 8-15 per cent less time providing child care, whereas Hispanic men spend 14 per cent more time providing child care than Hispanic women. This finding is interesting, as it shows that among Hispanics, the odds of providing child care are lower among men than among women, but that those men who are caregivers tend to spend more time providing care than women. The results also show that, on average, foreign-born Mexicans and Latino Americans spend 5.1 more minutes per day on child care than U.S.- and Canadianborn Americans. Although this difference is insubstantial in practical terms, it provides some support for our hypothesis 2. A similar effect is observed in the adult care models for African American men, as these men provide up to 72 per cent, or 14 additional minutes, of the adult care provided on an average day (this is likely spousal or sibling care, given the corresponding pattern observed in Figure A.1). The patterns for Asians are not significantly different from the patterns for non-Hispanic whites, once the socio-economic and household structure effects are controlled for in models 4 and 5. All else being equal, non-Hispanic men spend 15-17 per cent significantly less time caring for children than women. However, no significant gender gap is found in the adult care models, except among African 
Table 3(a):

Ordinary Least Squares models predicting $\log _{\mathrm{e}}$ minutes per day of child care (coefficients exponentiated). Coefficients represent ratios relative to the baseline

\begin{tabular}{|c|c|c|c|c|c|c|}
\hline & (1) & (2) & (3) & (4) & (5) & (6) \\
\hline (Intercept) & $89.71^{* * *}$ & $92.87^{* * *}$ & $92.87^{* * *}$ & $57.73^{* * *}$ & $56.89^{* * *}$ & $56.14^{* * *}$ \\
\hline Age & $1.02^{* * *}$ & $1.02^{* * *}$ & $1.02^{* * *}$ & $1.07^{* * *}$ & $1.06^{* * *}$ & $1.06^{* * *}$ \\
\hline Age squared & $1.00^{* * *}$ & $1.00^{* * *}$ & $1.00^{* * *}$ & $1.00^{* * *}$ & $1.00^{* * *}$ & $1.00^{* * *}$ \\
\hline \multicolumn{7}{|l|}{ Sex (female ref.) } \\
\hline Male & $0.74^{* * *}$ & $0.72^{* * *}$ & $0.72^{* * *}$ & $0.84^{* * *}$ & $0.82^{* * *}$ & $0.85^{* * *}$ \\
\hline \multicolumn{7}{|l|}{$\begin{array}{l}\text { Race/ethnicity } \\
\quad \text { (non-Hispanic white ref.) }\end{array}$} \\
\hline Non-Hispanic black & & $0.85^{* * *}$ & $0.86^{* * *}$ & $0.89^{* *}$ & $0.92^{*}$ & \\
\hline Non-Hispanic Asian & & $0.84^{*}$ & $0.84^{*}$ & 0.88 & 0.91 & \\
\hline Hispanic of any race & & $0.90^{* *}$ & $0.90^{* *}$ & $0.93^{*}$ & 0.94 & \\
\hline \multicolumn{7}{|l|}{ Nativity (U.S./Canada ref.) } \\
\hline Born in Europe & & 1.10 & 1.14 & 1.10 & 1.11 & \\
\hline $\begin{array}{l}\text { Born in West/Central } \\
\text { Asia }\end{array}$ & & $1.37^{*}$ & $1.42^{*}$ & $1.20^{*}$ & 1.19 & \\
\hline Born in East Asia & & 1.12 & 1.17 & 1.22 & 1.20 & \\
\hline $\begin{array}{l}\text { Born in Latin America } \\
\text { or Mexico }\end{array}$ & & 1.06 & 1.10 & $1.09^{*}$ & $1.09^{*}$ & \\
\hline Born in Africa & & 0.87 & 0.89 & 1.07 & 1.04 & \\
\hline $\begin{array}{l}\text { Born in Australia } \\
\text { or New Zealand }\end{array}$ & & 1.55 & 1.59 & 1.92 & 1.79 & \\
\hline \multicolumn{7}{|l|}{$\begin{array}{l}\text { Decade of immigration } \\
\text { (native-born ref.) }\end{array}$} \\
\hline Prior to 1950 & & 0.78 & 0.78 & & & \\
\hline 1950-1959 & & 0.70 & 0.64 & & & \\
\hline 1960-1969 & & 0.79 & 0.89 & & & \\
\hline 1970-1979 & & 1.01 & 0.88 & & & \\
\hline 1980-1989 & & 1.05 & 1.02 & & & \\
\hline 1990-1999 & & 0.94 & 0.90 & & & \\
\hline 2000 onward & & 1.18 & 1.15 & & & \\
\hline $\begin{array}{l}\text { Family income } \\
\qquad(\$ 25,000 \text { increments })\end{array}$ & & & & $1.01^{*}$ & 1.01 & 1.01 \\
\hline \multicolumn{7}{|l|}{$\begin{array}{l}\text { Educational attainment } \\
\text { (<high school ref.) }\end{array}$} \\
\hline High school & & & & $1.11^{* *}$ & $1.15^{* * *}$ & $1.11^{* * *}$ \\
\hline Some college/college & & & & $1.25^{* * *}$ & $1.28^{* * *}$ & $1.22^{* * *}$ \\
\hline Professional/Ph.D. & & & & $1.46^{* * *}$ & $1.48^{* * *}$ & $1.43^{* * *}$ \\
\hline \multicolumn{7}{|l|}{$\begin{array}{l}\text { School enrolment } \\
\text { (not in school ref.) }\end{array}$} \\
\hline Enrolled & & & & $0.71^{* * *}$ & $0.72^{* * *}$ & $0.70^{* * *}$ \\
\hline
\end{tabular}

Continued 
Table 3(a):

Continued

\begin{tabular}{|c|c|c|c|c|c|c|}
\hline & (1) & (2) & (3) & (4) & (5) & (6) \\
\hline \multicolumn{7}{|l|}{$\begin{array}{l}\text { Employment status } \\
\text { (employed ref.) }\end{array}$} \\
\hline Unemployed & & & & $1.23^{* * *}$ & $1.24^{* * *}$ & $1.22^{* * *}$ \\
\hline Not in labour force & & & & $1.36^{* * *}$ & $1.31^{* * *}$ & $1.30^{* * *}$ \\
\hline Hours spent working & & & & $0.95^{* * *}$ & $0.95^{* * *}$ & $0.95^{* * *}$ \\
\hline Presence of spouse or partner & & & & & $1.07^{*}$ & $1.10^{* * *}$ \\
\hline Num. of HH children under 18 & & & & & $1.09^{* * *}$ & $1.09^{* * *}$ \\
\hline Num. of other $\mathrm{HH}$ adults & & & & & $0.94^{* * *}$ & $0.94^{* * *}$ \\
\hline \multicolumn{7}{|l|}{ Interactions } \\
\hline Male $\times$ Non-Hispanic black & & 1.09 & 1.09 & 1.01 & 1.01 & \\
\hline Male $\times$ Non-Hispanic Asian & & $1.33^{*}$ & $1.32^{*}$ & 1.30 & 1.28 & \\
\hline Male $\times$ Hispanic of any race & & $1.21^{* *}$ & $1.21^{* *}$ & $1.14^{*}$ & $1.14^{*}$ & \\
\hline Male $\times$ Born in Europe & & $0.75^{*}$ & 0.67 & 0.81 & 0.81 & \\
\hline $\begin{array}{l}\text { Male } \times \text { Born in West } / \\
\text { Central Asia }\end{array}$ & & $0.68^{* *}$ & $0.62^{*}$ & 0.78 & 0.80 & \\
\hline Male $\times$ Born in East Asia & & 0.89 & 0.81 & 0.86 & 0.87 & \\
\hline $\begin{array}{l}\text { Male } \times \text { Born in Latin } \\
\text { America or Mexico }\end{array}$ & & 0.90 & 0.82 & 1.04 & 1.04 & \\
\hline Male $\times$ Born in Africa & & 0.93 & 0.85 & 0.89 & 0.88 & \\
\hline $\begin{array}{l}\text { Male } \times \text { Born in Australia } \\
\text { or New Zealand }\end{array}$ & & 0.75 & 0.69 & 0.71 & 0.76 & \\
\hline $\begin{array}{l}\text { Male } \times \text { Immigrated } \\
\text { prior to } 1950\end{array}$ & & & - & & & \\
\hline $\begin{array}{l}\text { Male } \times \text { Immigrated } \\
\text { in } 1950-1959\end{array}$ & & & 1.19 & & & \\
\hline $\begin{array}{l}\text { Male } \times \text { Immigrated } \\
\text { in } 1960-1969\end{array}$ & & & 0.72 & & & \\
\hline $\begin{array}{l}\text { Male } \times \text { Immigrated } \\
\text { in } 1970-1979\end{array}$ & & & 1.42 & & & \\
\hline $\begin{array}{l}\text { Male } \times \text { Immigrated } \\
\text { in } 1980-1989\end{array}$ & & & 1.09 & & & \\
\hline $\begin{array}{l}\text { Male } \times \text { Immigrated } \\
\text { in 1990-1999 }\end{array}$ & & & 1.14 & & & \\
\hline $\begin{array}{l}\text { Male } \times \text { Immigrated } \\
\text { in } 2000 \text { onward }\end{array}$ & & & 1.06 & & & \\
\hline $\mathrm{R}^{2}$ & 0.039 & 0.047 & 0.048 & 0.136 & 0.146 & 0.142 \\
\hline Adjusted $\mathrm{R}^{2}$ & 0.039 & 0.045 & 0.045 & 0.134 & 0.144 & 0.141 \\
\hline $\mathrm{F}$ & $202.2^{* * *}$ & $25.6^{* * *}$ & $21.2^{* * *}$ & $69.9^{* * *}$ & $68.8^{* * *}$ & $155.9^{* * *}$ \\
\hline
\end{tabular}

Note: ${ }^{* * *} p<0.001,{ }^{* *} p<0.01,{ }^{*} p<0.05$. 
Table 3(b):

Ordinary Least Squares models predicting $\log _{\mathrm{e}}$ minutes per day of adult care (coefficients exponentiated). Coefficients represent ratios relative to the baseline

\begin{tabular}{|c|c|c|c|c|c|c|}
\hline & (1) & (2) & (3) & (4) & (5) & (6) \\
\hline (Intercept) & $19.00^{* * *}$ & $17.97^{* * *}$ & $18.12^{* * *}$ & $25.47^{* * *}$ & $19.40^{* * *}$ & $20.89^{* * *}$ \\
\hline Age & 1.01 & 1.01 & 1.01 & 0.99 & 1.01 & 1.02 \\
\hline Age squared & 1.00 & 1.00 & 1.00 & 1.00 & 1.00 & 1.00 \\
\hline \multicolumn{7}{|l|}{ Sex (female ref.) } \\
\hline Male & 0.99 & 0.93 & 0.92 & 0.86 & 0.86 & 0.91 \\
\hline \multicolumn{7}{|l|}{$\begin{array}{l}\text { Race/ethnicity } \\
\quad \text { (non-Hispanic white ref.) }\end{array}$} \\
\hline Non-Hispanic black & & 1.17 & 1.16 & 0.96 & 0.94 & \\
\hline Non-Hispanic Asian & & 0.79 & 0.79 & 0.96 & 0.91 & \\
\hline Hispanic of any race & & 0.95 & 0.95 & 0.98 & 0.92 & \\
\hline \multicolumn{7}{|l|}{ Nativity (U.S./Canada ref.) } \\
\hline Born in Europe & & 1.08 & 1.42 & 1.14 & 1.15 & \\
\hline Born in West/Central Asia & & 1.47 & 2.01 & 1.73 & 1.73 & \\
\hline Born in East Asia & & 0.95 & 1.27 & 1.03 & 0.93 & \\
\hline $\begin{array}{l}\text { Born in Latin America } \\
\text { or Mexico }\end{array}$ & & 1.14 & 1.50 & 1.35 & 1.49 & \\
\hline Born in Africa & & 0.96 & 1.35 & 0.77 & 0.80 & \\
\hline $\begin{array}{l}\text { Born in Australia } \\
\text { or New Zealand }\end{array}$ & & 0.81 & 1.06 & 0.40 & 0.50 & \\
\hline \multicolumn{7}{|l|}{$\begin{array}{l}\text { Decade of immigration } \\
\text { (native-born ref.) }\end{array}$} \\
\hline Prior to 1950 & & 0.90 & 0.23 & & & \\
\hline 1950-1959 & & 1.10 & 1.05 & & & \\
\hline 1960-1969 & & 1.79 & 1.38 & & & \\
\hline 1970-1979 & & 1.38 & 1.12 & & & \\
\hline 1980-1989 & & 1.22 & 1.06 & & & \\
\hline 1990-1999 & & 1.22 & 0.87 & & & \\
\hline 2000 onward & & 1.24 & 0.88 & & & \\
\hline $\begin{array}{l}\text { Family income } \\
\qquad(\$ 25,000 \text { increments })\end{array}$ & & & & $0.93^{*}$ & $0.92^{* *}$ & $0.92^{* *}$ \\
\hline \multicolumn{7}{|l|}{$\begin{array}{l}\text { Educational attainment } \\
\text { (<high school ref.) }\end{array}$} \\
\hline High school & & & & 1.22 & 1.07 & 0.96 \\
\hline Some college/college & & & & 1.15 & 1.05 & 0.95 \\
\hline Professional/Ph.D. & & & & 0.91 & 0.84 & 0.80 \\
\hline \multicolumn{7}{|l|}{$\begin{array}{l}\text { School enrolment } \\
\text { (not in school ref.) }\end{array}$} \\
\hline Enrolled & & & & 0.92 & 0.94 & 0.91 \\
\hline
\end{tabular}

\section{Continued}


Table 3(b):

Continued

\begin{tabular}{|c|c|c|c|c|c|c|}
\hline & (1) & (2) & (3) & (4) & (5) & (6) \\
\hline \multicolumn{7}{|l|}{$\begin{array}{l}\text { Employment status } \\
\text { (employed ref.) }\end{array}$} \\
\hline Unemployed & & & & 1.13 & 1.11 & 1.11 \\
\hline Not in labour force & & & & $0.75^{*}$ & $0.78^{*}$ & $0.76^{*}$ \\
\hline Hours spent working & & & & $0.96^{* * *}$ & $0.96^{* * *}$ & $0.96^{* *}$ \\
\hline Presence of spouse or partner & & & & & 1.12 & 1.17 \\
\hline Num. of $\mathrm{HH}$ children under 18 & & & & & $0.91^{* *}$ & $0.92^{*}$ \\
\hline Num. of HH adults & & & & & $1.13^{* *}$ & $1.14^{* *}$ \\
\hline \multicolumn{7}{|l|}{ Interactions } \\
\hline Male $\times$ Non-Hispanic black & & $1.46^{*}$ & $1.46^{*}$ & $1.76^{*}$ & $1.72^{*}$ & \\
\hline Male $\times$ Non-Hispanic Asian & & 1.40 & 1.53 & 1.51 & 1.49 & \\
\hline Male $\times$ Hispanic of any race & & 1.08 & 1.06 & 0.91 & 0.93 & \\
\hline Male $\times$ Born in Europe & & 0.98 & 0.57 & 0.65 & 0.74 & \\
\hline Male $\times$ Born in West/Central Asia & & 1.04 & 0.47 & 1.42 & 1.65 & \\
\hline Male $\times$ Born in East Asia & & 1.02 & 0.41 & 1.23 & 1.55 & \\
\hline $\begin{array}{l}\text { Male } \times \text { Born in Latin America } \\
\text { or Mexico }\end{array}$ & & 1.06 & 0.52 & 1.28 & 1.09 & \\
\hline Male $\times$ Born in Africa & & 0.67 & 0.30 & 1.10 & 1.02 & \\
\hline $\begin{array}{l}\text { Male } \times \text { Born in Australia } \\
\text { or New Zealand }\end{array}$ & & 0.45 & 0.20 & 1.28 & 1.34 & \\
\hline $\begin{array}{l}\text { Male } \times \text { Immigrated } \\
\text { prior to } 1950\end{array}$ & & & $14.97^{*}$ & & & \\
\hline $\begin{array}{l}\text { Male } \times \text { Immigrated } \\
\text { in } 1950-1959\end{array}$ & & & 0.99 & & & \\
\hline $\begin{array}{l}\text { Male } \times \text { Immigrated } \\
\text { in 1960-1969 }\end{array}$ & & & 1.65 & & & \\
\hline $\begin{array}{l}\text { Male } \times \text { Immigrated } \\
\text { in } 1970-1979\end{array}$ & & & 1.90 & & & \\
\hline $\begin{array}{l}\text { Male } \times \text { Immigrated } \\
\text { in 1980-1989 }\end{array}$ & & & 1.49 & & & \\
\hline $\begin{array}{l}\text { Male } \times \text { Immigrated } \\
\text { in 1990-1999 }\end{array}$ & & & 2.36 & & & \\
\hline $\begin{array}{l}\text { Male } \times \text { Immigrated } \\
\text { in } 2000 \text { onward }\end{array}$ & & & 2.36 & & & \\
\hline $\mathrm{R}^{2}$ & 0.021 & 0.040 & 0.043 & 0.060 & 0.076 & 0.052 \\
\hline Adjusted $\mathrm{R}^{2}$ & 0.020 & 0.029 & 0.029 & 0.037 & 0.051 & 0.042 \\
\hline $\mathrm{F}$ & $18.1^{* * *}$ & $3.65^{* * *}$ & $3.11^{* * *}$ & $2.67^{* * *}$ & $3.12^{* * *}$ & $5.03^{* * *}$ \\
\hline
\end{tabular}

Note: ${ }^{* * *} p<0.001,{ }^{* *} p<0.01,{ }^{*} p<0.05$. 
Americans. Overall, the child care intensity diminishes from about 1.5 hours per day on average at baseline in models $1-3$ to just under one hour as soon as the socio-economic and household structure factors are introduced in models 4-6. As predicted, we see that the propensity to provide child care grows with age. In a slightly curvilinear pattern, these odds decline 0.2 per cent per year of age above age 15. This finding is expected given the tendency for care time commitment levels to increase during the reproductive years, and then to decline slowly but steadily through retirement. Models 2 and 3 of both child care and adult forms of care test the effect of the duration of stay in the U.S. for immigrants. Neither the main effects, nor the interactions with the decade of immigration, are found to have any impact on the model and its fit, and are thus excluded from consideration in models 4-6 shown in Tables 3(a) and 3(b). This finding suggests that the temporal aspect of cultural assimilation to the informal care arrangements of U.S. is not sufficiently strong to set immigrants apart from the native-born population, while holding the rest of the demographic, socio-economic, and household structural attributes fixed. As predicted, the effects of household structure, employment, and educational factors are significant. For example, people who work longer hours spend 5 per cent less time providing child care per hour of work than those who are unemployed or out of labour force, whereas people who have advanced degrees or professional education spend nearly 48 per cent more time on child care than those without a high school diploma. Like in the logistic model, most of the results are rendered insignificant for adult care, except for the effects of occupational and household structure characteristics. Occupational characteristics are negatively associated with involvement in adult care, perhaps because people who are working tend to outsource the adult care tasks they are unable or unwilling to perform. By contrast, the number of adults in the household is positively associated with involvement in adult care. On the other hand, unlike in the child care models, the presence of a spouse or a partner does not appear to be a significant predictor of providing adult care, regardless of the individual's racial/ethnic or national background. However, family income is one of the primary predictors in the adult care models, with income being negatively associated with the amount of time transferred. This pattern may be attributed to these individuals having less time to provide adult care because they are spending more time working. Educational characteristics do not seem to affect the likelihood of providing adult care.

Looking at the OLS model fit, we see that adding individual and family socioeconomic variables increases the fit of both the child care models and, to lesser extent, the adult care models. The comparison of the child care and the adult care models 3 and 4, and 5 and 6 demonstrates that race/ethnicity and nativity factors make no substantial contributions to explaining the variance. The fully specified models 5 and 6 , excluding race/ethnicity, nativity, and pertinent interactions, predict 56.9 and 56.1 minutes of child care and 19.4 and 20.9 minutes of adult care, respectively, at the baseline; with few changes in the common model coefficients or standard errors. The inclusion and the subsequent exclusion of race/ethnicity and nativity leave the model fit largely unaltered. The observed increases in R-squared 
from model 2 to model 3 , and its subsequent decreases from model 5 to 6 , are negligible. These findings are additional evidence contradicting hypothesis 4 ; i.e. that race/ethnicity and nativity are cultural proxy variables that are as important as socio-economic and household structure factors in explaining caregiving patterns.

\subsection{Care support ratio}

The matrices discussed above depict several distinct caregiving patterns. Although these patterns provide a nice quantitative summary of transfers by age, sex, and race/ethnicity, they could also shed light on the ongoing discussion in developed countries about how to deal with increasing levels of economic dependency. Considerable efforts have been made to study the allocation and the redistribution of tangible resources across various sub-populations within the National Transfer Accounts (NTA) framework (Lee and Mason 2011). It is not difficult to deduce from these analyses that the availability and the use of non-monetary resources depend on the availability and the use of economic resources. However, non-market transfers, such as time spent on routine household chores and caregiving, have been largely overlooked in these studies because they are difficult to measure. We propose adding a complementary measure of economic dependency to the NTA Support Ratio (SR) that relates the sum value of goods and services produced in a country to the sum value of the goods and services consumed. In this case, we define the care support ratio (CSR) as the ratio of the aggregate care time produced through informal activities to the aggregate care time consumed in a year. The key difference between the SR and CSR is that, unlike money, time cannot be saved for later use, and is consumed at the time of its production by very specific groups of individuals. Using this approach, we construct profiles of household consumption and production by age for all racial and ethnic groups that allow us to calculate the CSR value of the care that is given and received within American households. We then project the calculated metric into the future by applying the rates of care time production and consumption to the dynamic population structure by age, sex, race, and ethnicity over time using published population projection estimates (U.S. Census Bureau 2014). We thus compare the CSR of household transfers to the overall country-level CSR calculated in our previous work (Dukhovnov and Zagheni 2015).

To calculate the CSR, we begin with the matrices analogous to those shown in Figures 1 and A.1, except that the cell values are changed to represent the national averages, unconditional on the caregiving status. While this approach makes the matrix appear bleaker and less informative, it is useful for this task. The matrices containing the national averages of time transferred by age, sex, race, and ethnicity are then aggregated into marginal sum profiles, which are exhibited in Figures 2, 3, and A.2. The equivalent profile set by national origin group is shown in Figure A.2 in the Appendix, but it is not used here for the purposes of CSR calculation due to the sparse matrix structure and the high standard errors associated with small sample sizes for immigrant groups. As we discussed earlier in Section 5.1, the 
basic message that these profiles convey is that the per capita productivity of informal care time production increases during the reproductive years, and that most care is consumed during the early childhood years. The underlying assumption here is that the total care time produced must be equal to the total care time consumed. Thus, to ensure the exact matching of the total production with the total consumption for the current estimates, we need to adjust the production by a small factor that is equal to the ratio of the total average production to the total average consumption. This is necessary to even out the small differences caused by rounding and the errors introduced by the assumptions made when allocating the time equally across multiple potential care recipients who are were simultaneously present during a single care activity. Then, to approximate the aggregate amount of care time produced and consumed in a country, we multiply the averages by group (i.e. the profile values) by the population size in the respective age groups and racial/ethnic categories. The ratio of the resultant two quantities, adjusted for parity of production and consumption in the base year (2014), equals the care support ratio. Finally, to project the future CSR, we apply the same adjusted rates of average care time production and consumption to the medium-fertility U.S. Census projected population counts (U.S. Census Bureau 2014) by age and race/ethnicity for each year of our projection, while assuming that the future rates will remain fixed at current levels.

Figure 4 shows the comparison of various CSRs. All group CSRs based on household production are estimated to remain above the value of one, indicating the excess care time generated by caregivers at present rates of production and the consumption by care recipients. Hispanics appear to be especially productive, as the CSR for this group is projected to increase over the next half-century until it reaches a value of around 1.2 by 2060 . Among African Americans, the increase in the CSR is projected to be half that of Hispanics. This discrepancy is mainly attributable to the higher prevalence of multigenerational households among Hispanics (Pew Research Center 2016).

However, even though Asians have a comparable probability of living in a multigenerational household, they have fewer children on average, and thus produce less care time per capita. Whites and Asians have similar socio-economic characteristics, and neither group shows a marked increase in output within households. The care support ratios of these groups are projected to be just 1.06 and 1.01 by 2060 , respectively; although neither group has a production deficit. However, this picture remains incomplete without the proper consideration of both household and nonhousehold transfers - which, as we discussed earlier, is difficult to do because of data limitations. It should be noted that at present, the vast majority of all transferred care time is produced and consumed within households.

The overall CSR of approximately 0.97 - which includes both places where time is transferred - indicates that there is a small but persistent total future deficit. Without being able to construct an accurate non-household measure of consumption based on ATUS data, it is difficult to pinpoint the cause of this shrinkage. Such a trend could reflect increased care demands by older people who typically reside 
Figure 4:

Projected overall and household care support ratios (CSR) for every major racial/ethnic group, 2014-2060

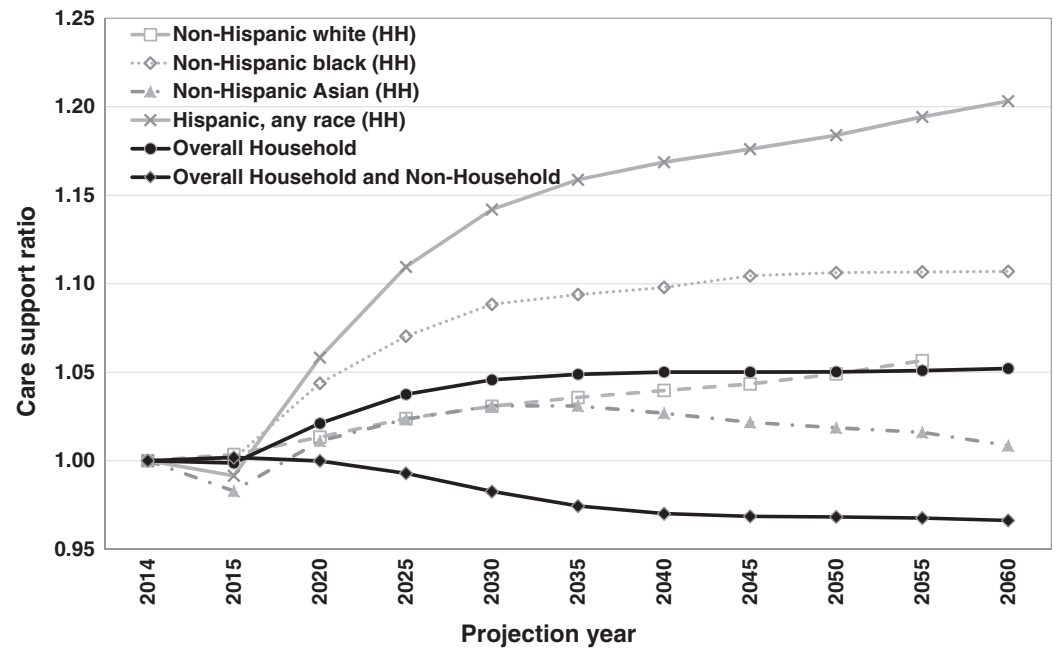

Note: The non-household care support ratio is not decomposed by race/ethnicity, since it requires several strong assumptions regarding the distribution of time to children of others and to non-household adults for whom the demographic information is often missing, as noted in Section 4. Some plausible assumptions were made in Dukhovnov and Zagheni (2015) about the overall transfers by age and sex. However, extending these assumptions to the disaggregation by race/ethnicity would not only increase uncertainty in our estimates due to the small size of the sample of non-household transfers; it would require us to assume that all racial/ethnic categories deliver care to specific groups outside of the caregiver household in the same manner. We have many reasons to doubt such generalisations.

outside of the caregiver's household, or decreased consumption of care due to the ongoing decline in fertility, especially among non-Hispanic whites and Asians. However, these explanations do not appear to hold for all racial/ethnic groups, such as Hispanics, whose cultural traditions predispose them to live in multigenerational households, and who are projected to remain younger and to continue to have more children on average. If, however, the Hispanic population sub-group undergoes further demographic changes, it is plausible that by the middle of the century the pool of middle-aged individuals in this group will increase. This development would in turn generate a sort of demographic dividend by increasing the potential aggregate amount of care Hispanics are capable of providing during their peak production years. On the other hand, the observed increases in the CSR may not materialise if fertility levels fall below those forecasted by the U.S. Census, or if caregiving rates change as a result of cultural, technological, or normative changes. We also need to be cognisant of the fertility differentials between the racial/ethnic groups. For example, Hispanics, who had the highest TFR (2.09) of any racial/ethnic group in the United States in 2016, are projected to to make up more 
than one-quarter of the U.S. population by 2050. As our CSR decomposition shows, it is likely that Hispanics will contribute a substantial share of the overall household CSR increase in the coming decades, although the nature of these transfers will likely change as their fertility is projected to decline. Moreover, as mortality is increasingly postponed and post-retirement lifespans grow longer among Hispanics, the incidence of adult care transfers in this group is expected to increase (Ortman et al. 2014).

\section{Discussion}

In this concluding section, we will address the hypotheses that we presented at the beginning of this article. In Dukhovnov and Zagheni (2015), we showed that in the U.S., women are the primary child care providers, as, on average, women produce larger daily amounts of care time than men in every ethnic/racial group even though, conditional on their involvement, Hispanic men provide a few more minutes of child care per day on average than Hispanic women. However, sex is not a significant predictor of adult care participation or intensity, except among African Americans, as African American men transfer more time on average than African American women to adult care recipients of similar ages (e.g. spouses and siblings). The further decomposition of the time transfers matrices by race and ethnicity confirms our hypothesis 1 qualitatively, albeit with sizeable differences between the racial/ethnic and nativity groups in the cumulative amount of time spent providing care. It is, moreover, clear that foreign-born women are far more likely than their male counterparts to be responsible for providing care. This gender gap in caregiving is especially evident among immigrants born in Central and West Asia. Therefore, we expect that in the future, the response trajectories for increases in female labour force participation will vary by racial/ethnic and national background. For some groups, and especially for native-born Hispanics, the gender line will likely blur, as men gradually become more involved in child care. For foreign-born African Americans and Hispanics, the differences may persist due to the strong gender norms and stereotypes that continue to dominate in their countries of origin.

The regression models offered further insights into the differences between groups in the prevalence and the intensity of care. The results of the logistic models partly contradict our second hypothesis, which states that Asian Americans and Hispanics have varying care patterns depending on their nativity status. In fact, we found that individuals who belong to different racial/ethnic or nativity groups differ little from American-born whites in their propensity to provide care, provided they have the same levels of education, occupational attributes, and household structures. It is plausible that the differences we observed in the matrices are the result of communal efforts; i.e. that Hispanics, Asians, and - albeit to a lesser extent African Americans spend less time per capita for some transfers, mainly because they are more likely to rely on broader social support networks than non-Hispanic whites. Indeed, survey selection bias could also impact the estimates of the fit. For example, in multigenerational households, there may be several caregivers, such 
as parents, siblings, and grandparents, each of whom provides only a fraction of the care time that a young child living in the household needs. Such residential arrangements contrast sharply with those of single-parent households, in which the ratio of caregivers to care recipients is low. However, as the ATUS interviews only one person per household, no activity diary information could be obtained from the other household members. Despite our best efforts to account for the presence of various household members in our models, we were unable to ascertain whether any of these individuals took part in any care activities that might have reduced the probability or the intensity of the provision of either form of care by the respondent. As has been noted in the literature, family networks and communal supports are important culturally-specific sources of care. Future studies may be able to produce more accurate representations of the average informal care frequency and duration, while controlling for the presence, function, and time commitment of specific household members.

Next, we discuss several differences for which family income was found to be a significant predictor of the odds of providing child care and adult care. Increasing family income raises the odds of providing care for children somewhat, but it decreases the odds of providing care for adults slightly. The estimate for adult care is consistent with our expectations. As adult care is often physically and psychologically taxing, families may choose to avoid it if their income permits. The finding that income positively predicts the odds of providing child care may be linked to the enhanced ability of higher-income families to support children. Nevertheless, as the results of the OLS models demonstrate, prevalence does not necessarily translate into intensity. Unlike providing adult care, providing child care is generally seen as a happy and fulfilling experience. Thus, child care responsibilities are almost universally accepted by people of all ethnicities and income levels. Moreover, in many cases, the income of an older adult is not as important as his/her lifetime savings. The old-age consumption profiles presented in this paper appear to be rather shallow largely because in the U.S., elderly people often tap into the formal care market and public services to obtain necessary care. Hence, although we found support for our hypothesis 3 , we think that personal income and savings might have a greater impact on both the probability and the volume of adult care flows.

In discussing our final hypothesis, we reiterate that it is doubtless the case that cultural values and traditions play a substantial part in differentiating the patterns of the prevalence and the intensity of child care and adult care activities. It appears, however, that race, ethnicity, and national origin only partly explain the consequences of the cultural effects of care we observed in our matrices and marginal transfer profile plots. These effects are described by our models to a very limited degree. In support of this claim, we showed by the exclusion at various points of race/ethnicity and nativity factors that the model fit in both the logistic and the OLS regressions scarcely changes, with no adverse effects on the remaining coefficients. Moreover, we did not detect any sign of resistance to assimilation among immigrants depending on the decade of their arrival in the U.S. We therefore believe that the patterns observed in the matrix figures may be the artefact of 
some other unmeasured behaviours, health conditions, preferences, or attitudes that could not be accurately modelled using conventional factors. While the ATUS has a number of advantages, including the flexibility and the granularity of its time use data, because it is a large cross-sectional national survey, it inevitably overlooks many details about the respondents, their social networks, and their household characteristics. Future research, perhaps using panel data, could aim to disentangle these issues by exploring individual characteristics, as well as less common factors and behaviours in the daily lives of individual group members, which could affect how they provide or use informal care within the household, and beyond.

The contribution of the present paper is thus two-fold. First, we documented the differences in informal care patterns between the major racial/ethnic and national origin groups in the U.S. We decomposed these transfers by age, sex, race/ethnicity, and national origin, and began to explore the possibilities for the development of tailored predictive models of non-monetary resource transfers in sub-populations. Second, we introduced the care support ratio (CSR) as a nonmarket metric that complements the economic support ratio (SR). At present rates, the future household informal care time surplus will be driven by Hispanics and non-Hispanic African Americans. However, given that the population is ageing rapidly and fertility is expected to decline through the middle of the century, we can reasonably expect the CSR to fall below one, indicating an overall care deficit. Such a deficit may arise due to shifts in demand from the large numbers of elderly people living outside of the households of working-age adults, and to the relative scarcity of care time production, given present rates. Future advances in technology, medicine, and changes in lifestyle all have the potential to bring the supply and the demand structure of informal care into balance. Our approach has significant implications for economic policy and research in the areas of public and private transfers, as well as for the ways in which they factor in economic and social support systems for the growing older population. We believe the application of our method to the care support ratio calculations will be seen as valuable by the global community of NT(T)A researchers who are studying macro-level flows of resources by incorporating previously unmeasured value into the models.

\section{Acknowledgements}

The research reported in this article was supported in part by the National Institute on Aging under the award number T32-AG000246.

\section{References}

Cox, C. and A. Monk 1993. Hispanic culture and family care of Alzheimer's patients. Health and Social Work 18(2): 92-100. 
Cravey, T. and A. Mitra 2011. Demographics of the sandwich generation by race and ethnicity in the United States. The Journal of Socio-Economics 40(3): 306-311. DOI: $10.1016 /$ j.socec.2010.12.003.

Dilworth-Anderson, P., B. H. Brummett, P. Goodwin, S. W. Williams, R. B. Williams and I. C. Siegler 2005. Effect of race on cultural justifications for caregiving. The Journals of Gerontology Series B: Psychological Sciences and Social Sciences 60(5): S257-S262. DOI: $10.1093 /$ geronb/60.5.S257.

Dilworth-Anderson, P., I. C. Williams and B. E. Gibson 2002. Issues of race, ethnicity, and culture in caregiving research: A 20-year review (1980-2000). The Gerontologist 42(2): 237-272.

Dukhovnov, D. and E. Zagheni 2015. Who takes care of whom in the United States? Time transfers by age and sex. Population and Development Review 41(2): 183-206.

Fox, J. and G. Monette 1992. Generalized collinearity diagnostics. Journal of the American Statistical Association 87(417): 178-183.

Fredriksen-Goldsen, K. I. and N. Farwell 2005. Dual responsibilities among Black, Hispanic, Asian, and white employed caregivers. Journal of Gerontological Social Work 43(4): 25-44. DOI: 10.1300/J083v43n0403.

Janus, A. L. and P. Doty 2018. Trends in informal care for disabled older Americans, 19822012. The Gerontologist 58(5): 863-871. DOI: 10.1093/geront/gnx076.

Knight, B. G. and P. Sayegh 2010. Cultural values and caregiving: The updated sociocultural stress and coping model. The Journals of Gerontology Series B: Psychological Sciences and Social Sciences 65B(1): 5-13. DOI: 10.1093/geronb/gbp096.

Lee, R. and A. Mason 2011. Population aging and the generational economy: A global perspective. Cheltenham, UK: Edward Elgar Publishing.

Mendez-Luck, C. A., G. J. Geldhof, K. P. Anthony, W. N. Steers, C. M. Mangione and R. D. Hays 2016. Orientation to the caregiver role among Latinas of Mexican origin. The Gerontologist 56(6): e99-e108. DOI: 10.1093/geront/gnw087.

Morrow, R. D. 1989. Southeast Asian child rearing practices: Implication for child and youth care workers. Child and Youth Care Quarterly 18(4): 273-287.

Neary, S. R. and D. F. Mahoney 2005. Dementia caregiving: The experiences of Hispanic/Latino caregivers. Journal of Transcultural Nursing 16(2): 163-170. DOI: $10.1177 / 1043659604273547$.

Ortman, J. M., V. A. Velkoff and H. Hogan 2014. An Aging Nation: The Older Population in the United States. P25-1140. Current Population Reports. U.S. Census Bureau, U.S. Department of Commerce.

Padilla, Y. C. and G. Villalobos 2007. Cultural responses to health among Mexican American women and their families. Family and Community Health 30: S24-S33.

Peek, M. K., R. T. Coward and C. W. Peek 2000. Race, aging, and care: Can differences in family and household structure account for race variations in informal care? Research on Aging 22(2): 117-142.

Pew Research Center 2016. Whites Less Likely than Other Racial, Ethnic Groups to Live in Multigenerational Households. Washington, DC. Retrieved on 15 November 2018 from http://www.pewresearch.org/fact-tank/2018/04/05/a-record-64-million-americanslive-in-multigenerational-households/ft_16-08-05_multigeneration_race_ethnicity/. 
Powers, S. M. and C. J. Whitlatch 2016. Measuring cultural justifications for caregiving in African American and White caregivers. Dementia 15(4): 629-645. DOI: $10.1177 / 1471301214532112$.

Radey, M. and K. L. Brewster 2007. The influence of race/ethnicity on disadvantaged mothers' child care arrangements. Early Childhood Research Quarterly 22(3): 379-393. DOI: 10.1016/j.ecresq.2007.05.004.

Scharlach, A. E., R. Kellam, N. Ong, A. Baskin, C. Goldstein and P. J. Fox 2006. Cultural attitudes and caregiver service use: Lessons from focus groups with racially and ethnically diverse family caregivers. Journal of Gerontological Social Work 47(1-2): 133-156. DOI: $10.1300 / \mathrm{J} 083 \mathrm{v} 47 \mathrm{n} 0109$.

Sun, F., R. Ong and D. Burnette 2012. The influence of ethnicity and culture on dementia caregiving: A review of empirical studies on Chinese Americans. American Journal of Alzheimer's Disease and Other Dementias 27(1): 13-22. DOI: $10.1177 / 1533317512438224$.

U.S. Census Bureau 2014. Projected Population by Single Year of Age, Sex, Race, Hispanic Origin and Nativity for the United States: 2014 to 2060. NP2014_D5. U.S. Census Bureau, Population Division. Retrieved on 21 November 2017 from https://www2.census.gov/ programs-surveys/popproj/datasets/2014/2014-popproj/np2014_d5.csv.

Whillans, A. V., E. W. Dunn, P. Smeets, R. Bekkers and M. I. Norton 2017. Buying time promotes happiness. Proceedings of the National Academy of Sciences 114(32): 85238527. DOI: 10.1073/pnas.1706541114.

Yunus, S. M. 2005. Childcare practices in three Asian countries. International Journal of Early Childhood 37(1): 39-56. 


\section{Appendix}

\section{Figure A.1:}

Matrices of care time transfers in $\log _{10}$ minutes per day, by age, sex, race, and ethnicity; conditional on positive caregiving status

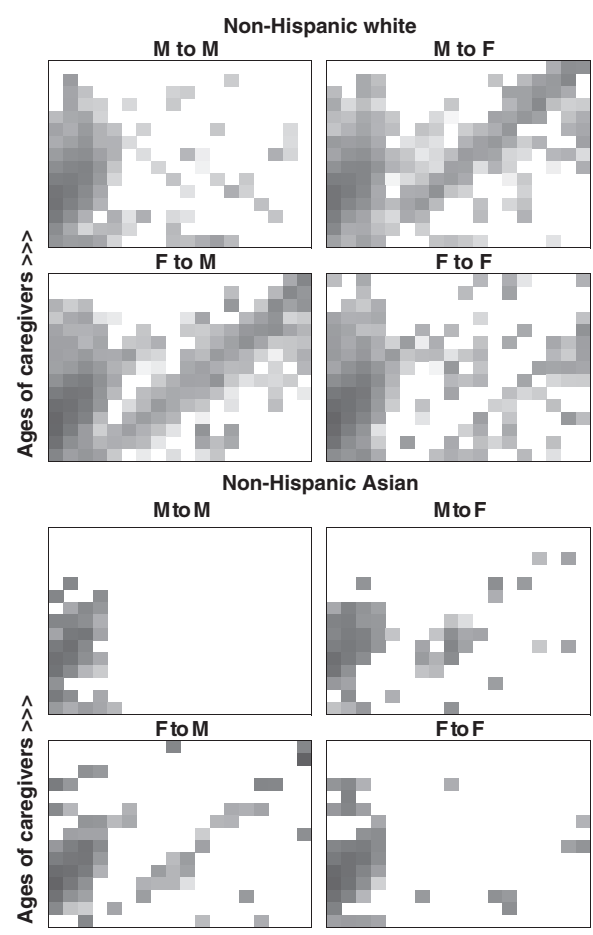

Ages of care recipients $\gg>$

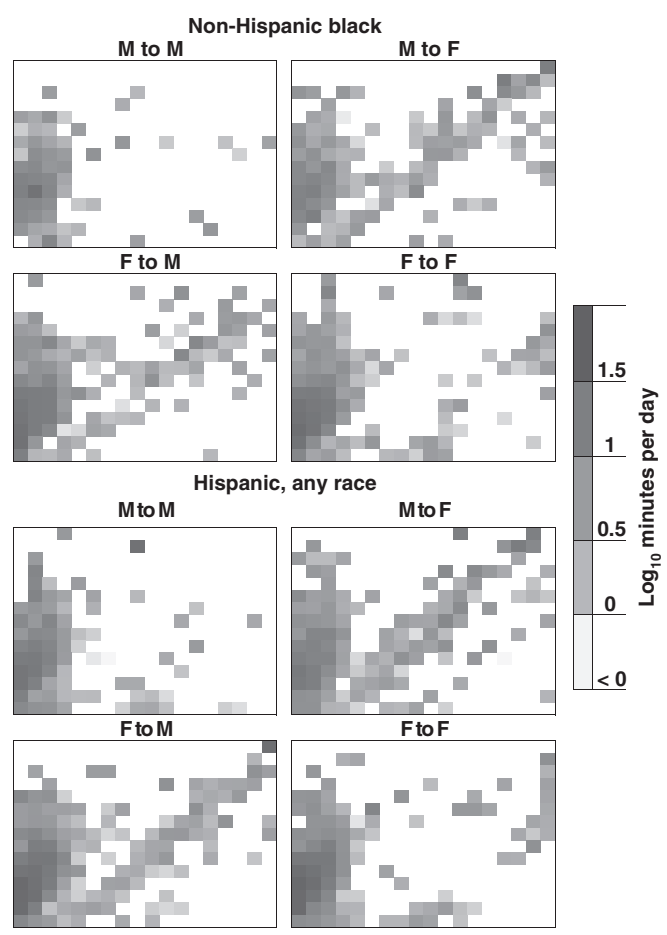

Ages of care recipients $\gg>$ 
Figure A.2:

Profiles of mean daily care time in hours: household production, consumption, and non-household production, by nativity
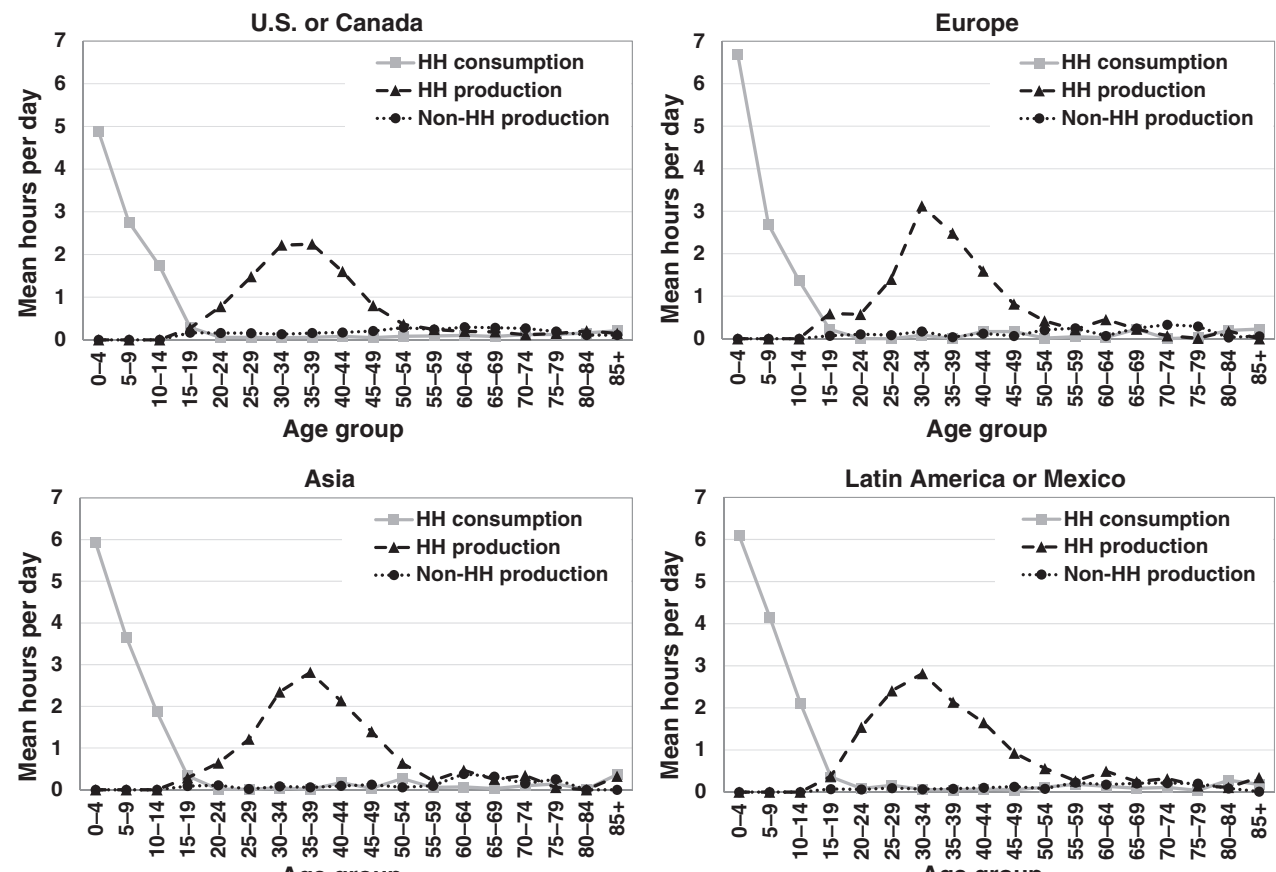

Age group
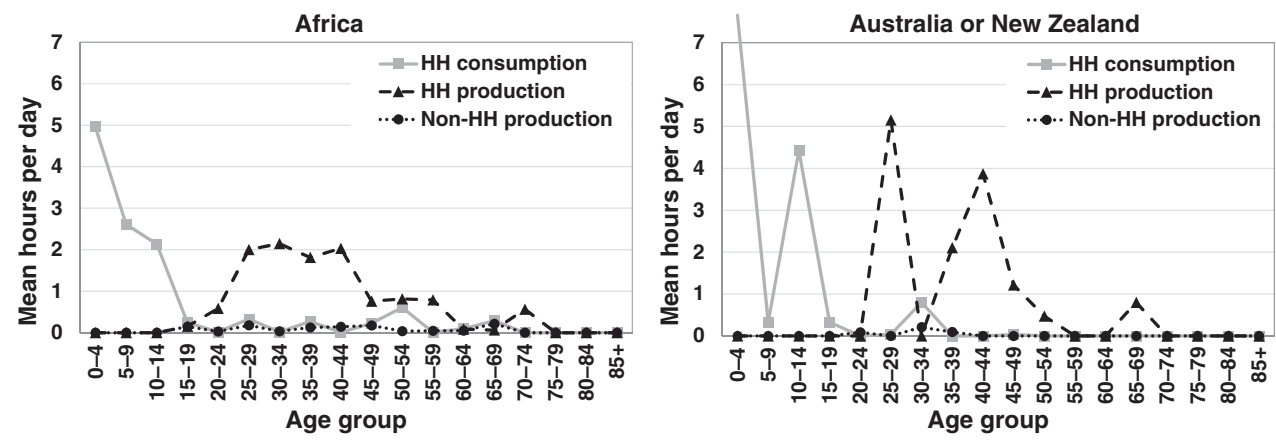
Table A.1:

2011-2015 ATUS total sample sizes by race and ethnicity and national origin

\begin{tabular}{|c|c|c|c|c|c|c|}
\hline \multirow[b]{2}{*}{ Place of birth } & \multicolumn{6}{|c|}{ Race and ethnicity } \\
\hline & $\begin{array}{l}\text { Non- } \\
\text { Hispanic } \\
\text { white }\end{array}$ & $\begin{array}{c}\text { Non- } \\
\text { Hispanic } \\
\text { black }\end{array}$ & $\begin{array}{c}\text { Non- } \\
\text { Hispanic } \\
\text { Asian }\end{array}$ & $\begin{array}{c}\text { Hispanic } \\
\text { of any } \\
\text { race }\end{array}$ & Undefined & Total \\
\hline U.S. \& Canada & 36703 & 7699 & 491 & 4229 & 960 & 50082 \\
\hline Europe & 1082 & 29 & 14 & 46 & 11 & 1182 \\
\hline West/Central Asia & 273 & 20 & 642 & 6 & 4 & 945 \\
\hline East Asia & 66 & 16 & 1055 & 13 & 48 & 1198 \\
\hline $\begin{array}{l}\text { Latin America } \\
\text { \& Mexico }\end{array}$ & 150 & 411 & 23 & 4246 & 8 & 4838 \\
\hline Africa & 98 & 370 & 13 & 4 & 5 & 490 \\
\hline $\begin{array}{l}\text { Australia and } \\
\text { New Zealand }\end{array}$ & 20 & 0 & 2 & 0 & 1 & 23 \\
\hline Undefined & 10 & 6 & 6 & 5 & 19 & 46 \\
\hline Total & 38402 & 8551 & 2246 & 8549 & 1056 & 58804 \\
\hline
\end{tabular}

